\title{
Global histone protein surface accessibility in yeast indicates a uniformly loosely packed genome with canonical nucleosomes
}

\author{
Luke T. Marr ${ }^{1}$, Josefina Ocampo ${ }^{2}$, David J. Clark ${ }^{3}$ and Jeffrey J. Hayes ${ }^{1 *}$ (D)
}

\begin{abstract}
Background: The vast majority of methods available to characterize genome-wide chromatin structure exploit differences in DNA accessibility to nucleases or chemical crosslinking. We developed a novel method to gauge genomewide accessibility of histone protein surfaces within nucleosomes by assessing reactivity of engineered cysteine residues with a thiol-specific reagent, biotin-maleimide (BM).

Results: Yeast nuclei were obtained from cells expressing the histone mutant H2B S116C, in which a cysteine resides near the center of the external flat protein surface of the nucleosome. BM modification revealed that nucleosomes are generally equivalently accessible throughout the S. cerevisiae genome, including heterochromatic regions, suggesting limited, higher-order chromatin structures in which this surface is obstructed by tight nucleosome packing. However, we find that nucleosomes within 500 bp of transcription start sites exhibit the greatest range of accessibility, which correlates with the density of chromatin remodelers. Interestingly, accessibility is not well correlated with RNA polymerase density and thus the level of gene expression. We also investigated the accessibility of cysteine mutations designed to detect exposure of histone surfaces internal to the nucleosome thought to be accessible in actively transcribed genes: $\mathrm{H3}$ 102, is at the $\mathrm{H} 2 \mathrm{~A}-\mathrm{H} 2 \mathrm{~B}$ dimer/H3-H4 tetramer interface, and $\mathrm{H} 3 \mathrm{~A} 110 \mathrm{C}$, resides at the $\mathrm{H} 3-\mathrm{H} 3$ interface. However, in contrast to the external surface site, we find that neither of these internal sites were found to be appreciably exposed.
\end{abstract}

Conclusions: Overall, our finding that nucleosomes surfaces within S. cerevisiae chromatin are equivalently accessible genome-wide is consistent with a globally uncompacted chromatin structure lacking substantial higher-order organization. However, we find modest differences in accessibility that correlate with chromatin remodelers but not transcription, suggesting chromatin poised for transcription is more accessible than actively transcribed or intergenic regions. In contrast, we find that two internal sites remain inaccessible, suggesting that such non-canonical nucleosome species generated during transcription are rapidly and efficiently converted to canonical nucleosome structure and thus not widely present in native chromatin.

Keywords: Subnucleosome, Chromatin structure, Transcription, Remodelers

*Correspondence: Jeffrey_Hayes@urmc.rochester.edu

${ }^{1}$ Department of Biochemistry and Biophysics, University of Rochester Medical Center, Rochester, NY 14642, USA

Full list of author information is available at the end of the article

\section{Background}

The vast majority of eukaryotic genomic DNA is assembled into nucleosomes, the basic repeating subunit of chromatin. In solutions containing physiological ionic strengths long chains of nucleosomes condense into higher order chromatin structures, facilitated by internucleosomal interactions mediated by the core histone

c) The Author(s) 2021. This article is licensed under a Creative Commons Attribution 4.0 International License, which permits use, sharing, adaptation, distribution and reproduction in any medium or format, as long as you give appropriate credit to the original author(s) and the source, provide a link to the Creative Commons licence, and indicate if changes were made. The images or other third party material in this article are included in the article's Creative Commons licence, unless indicated otherwise in a credit line to the material. If material is not included in the article's Creative Commons licence and your intended use is not permitted by statutory regulation or exceeds the permitted use, you will need to obtain permission directly from the copyright holder. To view a copy of this licence, visit http://creativeco mmons.org/licenses/by/4.0/. The Creative Commons Public Domain Dedication waiver (http://creativecommons.org/publicdomain/ zero/1.0/) applies to the data made available in this article, unless otherwise stated in a credit line to the data. 
'tail' domains [1-3]. While the exact arrangement of nucleosomes within such structures is in debate, most models for higher order structures involve packing and stacking of the disk-shaped nucleosomes along their flat surfaces [2, 4, 5]. Indeed individual nucleosome core particles at high concentrations, and osmotic pressures spontaneously stack in columnar structures of various configurations dependent on ionic conditions [6-12]. Nucleosome-nucleosome interactions are stabilized by linker histones, and may occur between nucleosomes in the same locality or between nucleosomes separated by large distances $[2,13]$.

Numerous non-histone chromatin factors govern the accessibility of genomic DNA within chromatin to regulate crucial biological processes, including gene expression. Some of these factors act by covalently adding or removing posttranslational modifications such as acetylation and phosphorylation on the core histones which alter electrostatic interactions that directly or indirectly alter chromatin structure [14-18]. Alternatively, such 'marks' can serve as binding sites for ancillary factors and activities such as ATP-dependent chromatin remodeling complexes and other architectural proteins that act to either enhance compaction or opening of the chromatin $[17,19-24]$. The culmination of these factors results in the activation of specific genes and commensurate decompaction of chromatin and increased accessibility of genomic DNA [25-27].

Efforts to map accessible, open regions of chromatin associated with active genes have relied on determining locations of differential accessibility of genomic DNA to nucleases such as DNase I, micrococcal nuclease, or chemical reagents. For example, DNA regions hypersensitive to DNase I were found to indicate open chromatin regions associated with active genes [27]. Formaldehydeassisted isolation of regulatory elements (FAIRE) also identifies open, histone-depleted DNA regions in chromatin, which are predominantly associated with promoters and enhancers [28]. More recently, ATAC-Seq has been used to identify accessible DNA regions in chromatin delimited by nucleosomes and other chromatin binding proteins $[29,30]$. While the commonly used micrococcal nuclease (MNase) efficiently excises nucleosome core particles, allowing detailed mapping of nucleosome occupancies, [31, 32], recent studies have shown that nucleosomes exhibit distinct rates of appearance and disappearance during MNase digestion, due to regional differences in DNA accessibility reflective of more open or closed global chromatin structures [33-35]. While much has been learned from assays gauging DNA accessibility, there are no techniques to assess how accessibility of the histone proteins varies with respect to genomic elements. Moreover, recent data indicate that accessibility to DNA probes does not strictly correlate with gene activity [35]. Therefore, an alternative measure of chromatin accessibility might provide further insight into how chromatin structure is altered to facilitate biological processes.

We previously described a method to probe the accessibility of surfaces of the core histones in the chromatin of $S$. cerevisiae nuclei. This method involves installation of a rationally selected cysteine substitution within a core histone and limited reaction with the thiol-specific reagent biotin-maleimide to determine the genome-wide accessibility of selected external and internal histone surfaces in nucleosomes. Measurements of histone surface accessibility provide insights complementary to chromatin accessibility derived from nucleases, such as MNase-Seq [36]. Here we monitor the accessibility of H2B S116C, located on an external surface of the nucleosome, the exposure of which is expected to be modulated through inter-nucleosomal interactions. Additionally, we probe the accessibility of two sites within the nucleosome core, H3 S102C and H3 A110C to survey generation of sub-nucleosomal structures in which the $\mathrm{H} 3-\mathrm{H} 3$ or the $\mathrm{H} 3 / \mathrm{H} 4-\mathrm{H} 2 \mathrm{~A} / \mathrm{H} 2 \mathrm{~B}$ interfaces are exposed, respectively. While we observe some differential accessibility for the external surface site, we find this site to be, in general, widely accessible throughout the $S$. cerevisiae genome. In stark contrast, we find little evidence of noncanonical nucleosome structures with exposed internal surfaces.

\section{Materials and methods}

\section{Yeast strains}

Generation of the H2B S116C mutant strain has previously been reported [36]. Briefly, a yeast strain (YDC 417) with one functional HTA-HTB locus (HTA2-HTB2 deleted) is transformed with an integration plasmid bearing the HTA1-HTB1 locus. The mutation of interest is made via site-directed mutagenesis. In addition to the HTA1-HTB1 locus, the plasmid also contains a functional copy of HIS3 which permits transformants to grow in histidine deficient media. Confirmation of proper integration and maintenance of mutation was performed by isolating the genomic DNA and sequencing the region of interest. For the $\mathrm{H} 3$ experiments, we used ROY1281 (MATalpha lys2 trp1 his3 leu2 ura3 hhf1-ht1 ::LEU2 hhf2-hht2.HIS3 pRO149 HHF1 HHT1 HTA1 HTB1 [37, 38]. H3 mutations are introduced onto plasmid p368 derived from pRS317 which contains a functional LYS2 gene [39]. As for H2B S116C, H3 mutations are introduced via Q5 site-directed mutagenesis (NEB E50554S) and sequence confirmed. However, the p368 plasmids are introduced into the strain through plasmid-shuffling rather than integration into the genomic DNA. The p368 plasmid is introduced to ROY1281 cells using the lithium acetate method and plated onto SC-LYS media to screen 
for transformants [40]. To obtain a strain containing only the p368 plasmid, transformants were inoculated and grown in SC-LYS medium and subsequently plated on SC-LYS with 5-FOA $(0.1 \%)$ to select for colonies which had exchanged $\mathrm{p} 368$ for $\mathrm{pRO} 149$ as this plasmid contains a functional $U R A 3$ whose presence will prevent growth on 5-FOA.

\section{Preparation of biotin-maleimide modified chromatin}

Nuclei from control and cells expressing histone mutants were prepared as in [41]. Briefly, yeast cultures were grown to mid-log phase $\left(\mathrm{OD}_{600} 0.5-0.8\right)$, treated with 6000 units of lyticase (Sigma Aldrich L2524), nuclei isolated with a Ficoll 400 cushion, then resuspended in MNase digestion buffer lacking $\beta$-mercapoethanol (BME) and $\mathrm{CaCl}_{2}$. Nuclei were modified with biotin-maleimide (BM, ThermoFisher Scientific 21901BID) as described in [36] with minor changes to account for modification times. BM was added to nuclei such that the final concentration was $100 \mu \mathrm{M}$ and mixed by pipetting up and down $10 \times$. Following mixing, $800 \mu \mathrm{L}(1 / 3$ of the reaction) was removed after $10 \mathrm{~s}, 1 \mathrm{~min}$, and $10 \mathrm{~min}$ of reaction, and transferred to a fresh tube containing $35 \mu \mathrm{L}$ of $140 \mathrm{mM}$ $\beta$-mercaptoethanol (BME, Sigma Aldrich M6250, final concentration $5 \mathrm{mM}$ ) to stop the reaction. Seven $\mu \mathrm{L}$ of $62.5 \mathrm{mM} \mathrm{CaCl}{ }_{2}$ was then added to final concentration of $\sim 0.5 \mathrm{mM}$ and the samples split into two aliquots for digestion with either 480 or 960 units of MNase (Worthington Biochemical LS004798) at room temperature for $3 \mathrm{~min}$. The amount of enzyme was empirically determined to yield predominantly mononucleosomes. Digestion was stopped by the addition of $100 \mu \mathrm{L}$ MNase stop solution (5 mM EDTA, 5 mM EGTA, 0.05\% NP-40) and held on ice for $2 \mathrm{~min}$. Samples are then treated as in [41] with $100 \mu \mathrm{L}$ of the final digested chromatin being used for analysis of DNA fragment sizes generated from the digestion, and the remaining $400 \mu \mathrm{L}$ of digested, BM modified chromatin stored at $-80^{\circ} \mathrm{C}$ until affinity purification.

\section{Affinity purification of biotin-maleimide modified nucleosomes}

A detailed protocol has previously been reported [36]. Briefly, $200 \mu \mathrm{L}$ of streptavidin-agarose (Solulink N-1000002) resin is washed once with $1 \times \mathrm{PBS} \mathrm{pH} 7.4$ and then $3 \times$ with $500 \mu \mathrm{L}$ of $1 \times \mathrm{PBS}$ pH 7.4 supplemented with $5 \mathrm{mg} / \mathrm{mL}$ BSA (NEB B9000S). MNase digested chromatin $(200 \mu \mathrm{L})$ is added to streptavidin-agarose and brought to a $1 \mathrm{~mL}$ volume with AP binding buffer $(10 \mathrm{mM}$ Tris $\mathrm{pH}$ 8.0, 1 mM EGTA, 0.05\% NP-40, $150 \mathrm{mM} \mathrm{NaCl}$, protease inhibitors (Sigma Aldrich 11873580001). Chromatin is incubated with streptavidin-agarose for $30 \mathrm{~min}$ at $4{ }^{\circ} \mathrm{C}$ and then washed once with AP binding buffer and twice with AP binding buffer supplemented with $600 \mathrm{mM}$
$\mathrm{NaCl}$. DNA from affinity purified nucleosomes is recovered with two $10 \mathrm{~min}$ treatments with elution buffer 1 (1\% SDS, $140 \mathrm{mM} \mathrm{NaCl}, 50 \mathrm{mM}$ Tris $\mathrm{pH}$ 8.0, $10 \mathrm{mM}$ EDTA) and elution buffer 2 (0.67\% SDS, $140 \mathrm{mM} \mathrm{NaCl}$, $50 \mathrm{mM}$ Tris pH 8.0, $10 \mathrm{mM}$ EDTA).

\section{Library preparation of input and affinity purified DNAs}

Library preparation was carried out with NEBNext ${ }^{\circledR}$ Ultra $^{\mathrm{TM}}$ DNA Library Prep Kit for Illumina ${ }^{\circledR}$ (New England BioLabs E7370) and NEBNext ${ }^{\circledR}$ Mutiplex Oligos for Illumina ${ }^{\circledR}$ (New England BioLabs E7335). In addition to yeast input and AP DNAs, we added $1 \mathrm{ng}$ or $10 \mathrm{ng}$ of mouse nucleosome core particle DNA to each sample prior to DNA repair step. This allowed us to standardize fold-enrichment in our experiments by analyzing the ratio of yeast reads to mouse reads between input and AP. A size selection step was not used in the library preparation, and it was found that $5 \mu \mathrm{L}$ of the adaptor ligated DNA coupled with ten cycles of the PCR conditions yielded sufficient material for sequencing.

\section{Data analysis of affinity purified and input DNAs}

Fastq files were aligned to reference genomes (SacCer2 or mm10) using the default parameters of Bowtie 2 to generate SAM files [42]. SAMtools was then used to generate BAM, sortedBAM and indexed BAM files using the default parameters [43]. BAM files were then used to generate bigwig files for individual input and AP files as well as AP/input files using deepTools bamCoverage and bamCompare [44]. For individual input and AP files using bamCoverage, the following arguments were used --binSize 10 --effectiveGenomeSize 12,100,000 --normalizeUsing RPKM --extendReads --ignoreDuplicates --minFragmentLength 135 --maxFragmentLength 165. For AP/input using bamCompare, the same arguments were used as for bamCoverage with the addition of --operation ratio. To map nucleosome fragments and determine accessibility, we employed computeMatrix and plotHeatmap from deepTools. Gene lists used to generate figures in this manuscript are cited in "Results" section. The determination of the amount of yeast DNA and ultimately the percentage of biotin-maleimide modified nucleosomes was accomplished by the inclusion of a known quantity of mouse NCP DNA, typically $1 \mathrm{ng}$, prior to DNA library preparation. The ratio of aligned yeast DNA reads with respect to mouse DNA reads was multiplied by the amount of spiked in mouse DNA to determine the amount of yeast DNA. In the case of the AP samples we applied a correction to account for the difference in MNase digested chromatin used to generate input and AP samples, as described in previous section, and that $10 \%$ of the input DNA compared to $100 \%$ of the AP DNA was used for library preparation. The amount 
of AP DNA is then divided by the amount of input DNA for each WT and H2B S116C time point to determine the percentage of H2B S116C modified nucleosomes at each time point. The values for WT were deemed to be background and therefore the average WT value was subtracted from each $\mathrm{H} 2 \mathrm{~B}$ S116C time point to determine the true percentage of $\mathrm{H} 2 \mathrm{~B}$ S116C modified nucleosomes ('corrected modified nucleosomes' in Additional file 1: Table S2).

\section{Results}

\section{Distinct nucleosome surface accessibility in genes}

We first sought to determine the extent to which the accessibility of an external histone protein surface on nucleosomes varies genome-wide among genes in yeast cells. We employed a new method in which modifiability of an engineered cysteine residue is probed with the thiol-specific reagent biotin maleimide (BM) [36]. The histone mutant $\mathrm{H} 2 \mathrm{~B}$ S116C places a cysteine exposed to solvent near the center of the flat protein surface of the nucleosome [36]. This surface is occluded upon condensation of oligonucleosome arrays [4, 45, 46], and upon nucleosome-nucleosome stacking in crystals and condensed liquid crystalline preparations of nucleosome core particles $[6,7,11,18,47]$. Indeed, we find that a cysteine at the corresponding site in Xenopus H2B (S112C) is more accessible in expanded oligonucleosome arrays than condensed arrays (results not shown). Freshly prepared nuclei from yeast cells expressing H2B S116C as the sole source of $\mathrm{H} 2 \mathrm{~B}$ were incubated with $\mathrm{BM}$, digested with micrococcal nuclease, and BM modified nucleosomes affinity-purified (AP) and sequenced
[36] (Additional file 1: Table S1). We first confirmed the expected nucleosome phasing (Fig. 1a). Phasing plots indicated virtually identical average nucleosome positioning/spacing over Pol II genes both WT and H2B S116C samples (Fig. 1a). We also examined the extent of nucleosome modification as a function of time as we wished to avoid saturating nucleosome modification sites to ensure distinction between nucleosomes with differentially accessible surfaces. Accordingly, we found about $0.4 \%$ of nucleosomes were modified when nuclei where incubated with BM for $10 \mathrm{~s}$, but the reaction reached an apparent limit of $3.1 \pm 1.4 \%$ of all nucleosomes modified at 1 and 10 min of modification, likely due to exhaustion of reagent upon reaction with the excess cysteine targets available in the nucleus (Fig. $1 \mathrm{~b}$ and Additional file 1: Table S2).

We next used the normalized AP and matched input data directly to determine nucleosome accessibility for the above data and replicate experiments (Additional file 1: Table S3). We aligned the genomic AP/input profiles according to transcription start sites (TSS) for 4166 yeast Pol II genes within a region $0.5 \mathrm{~kb}$ upstream to $1.5 \mathrm{~kb}$ downstream of the TSS (referred to as 'whole gene' analysis) and plotted the data averaged for all genes for each time point (Fig. 2a, top). Thus, an accessible or 'enriched' nucleosome would exhibit an AP/input score greater than 1, whereas an inaccessible nucleosome would exhibit a score less than 1 . The profiles show an average nucleosome enrichment of approximately 1 over the selected $2 \mathrm{~kb}$ region encompassing the TSS, including the nucleosome depleted region. However, we observe a small peak in enrichment just downstream of the TSS,
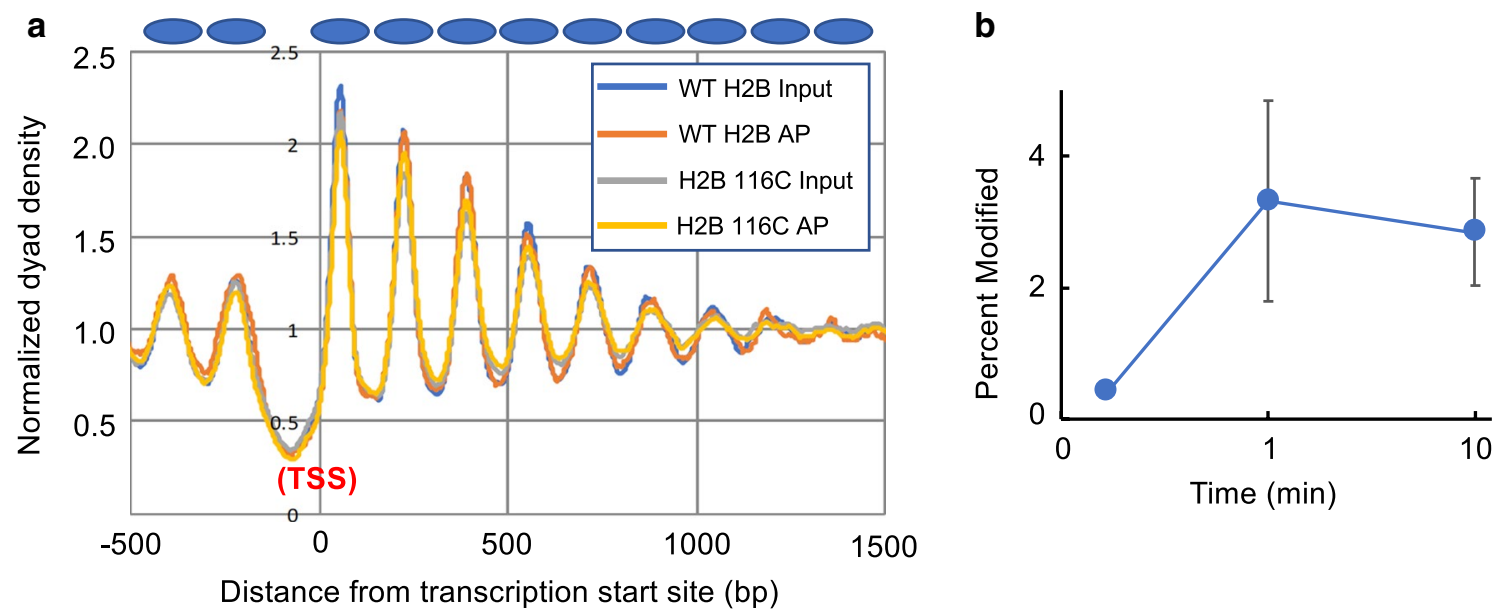

Fig. 1 a Nucleosome phasing plots for input and affinity purified (AP) samples from WT and H2B S116C cells, as indicated. Plots were aligned to the transcription start sites (TSS) of yeast genes and normalized to total reads for each data set. b Percent nucleosomes modified by biotin maleimide. Modification was carried out for 10 s, 1 and 10 min, as described in the text. Values were derived from data in Additional file 1: Table S2 as described in "Materials and methods" 


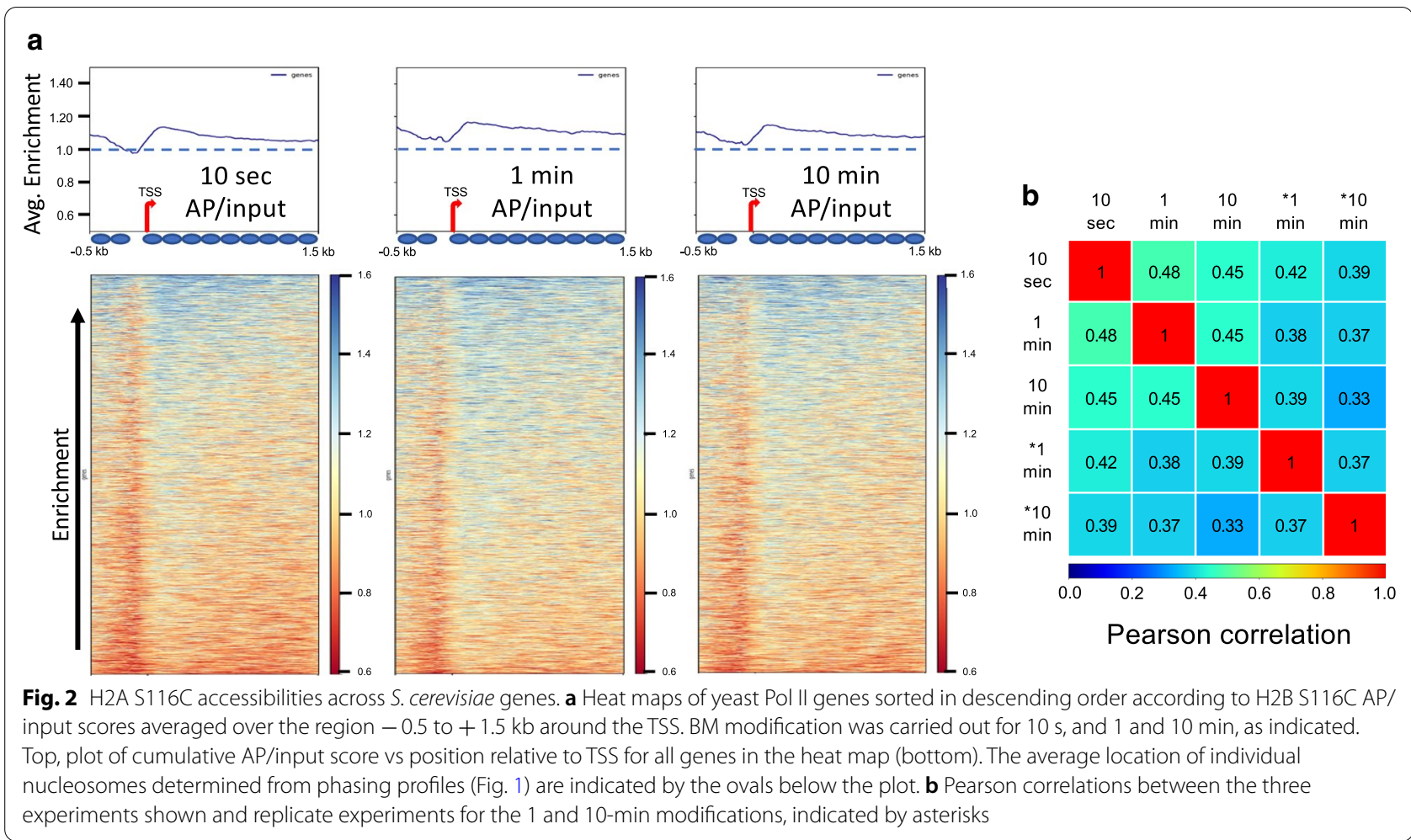

which tails off further into the gene, and a slightly lower score across the NDR, likely due to a de-enrichment of non-nucleosomal species in the AP. These results indicate that, in aggregate, Pol II genes exhibit accessibilities that are slightly higher than the genomic average but approximately equivalent through the upstream and downstream region.

To determine whether yeast genes exhibit differential accessibilities, we sorted genes aligned by TSS according to average $\mathrm{AP} /$ input enrichment score for each gene. Comparison of results from the three time points and replicate experiments (Additional file 1: Tables S1-S3) indicates that yeast genes exhibit a range of nucleosome surface accessibilities (Fig. 2a, heatmaps). The average correlation of gene ordering according to $\mathrm{AP} /$ input score between time points and independent experiments was moderate but significant $(\sim 0.40$ Pearson correlation, TSS to TTS) (Fig. 2b). We generated box and whisker plots of the average AP/input score for all genes to gauge the range of accessibility scores between each experiment (Fig. 3a). We find that the mean and medians are almost identical within and across experiments (Fig. 3a and Additional file 1: Table S4A). Calculation of the interquartile range (IQR) reveals the middle $50 \%$ of the $\mathrm{AP} /$ input scores are distributed over a relatively narrow range with an average IQR of 0.141 . To further understand the data, we plotted average accessibility scores for each data set as a function of gene order (Fig. 3c, blue line). The scores for the middle $80 \%$ of genes only cover a 1.3 -fold range from 0.96 to 1.25 , while the average of the top and bottom $5 \%$ of scores $(1.38 \pm 0.08$ and $0.9 \pm 0.03$, respectively) exhibits a range of $\sim 1.5$. These findings indicate that most genes, on average over the nucleosomes within the $2 \mathrm{~kb}$ region immediately surrounding the TSS, have relatively similarly accessible protein surfaces.

We then focused on the first $\sim 500 \mathrm{bp}$ of genes, which exhibited a peak in accessibility compared to more upstream and distal regions, and an apparent greater variability among genes (Fig. 2a, top). We resorted genes according to average $\mathrm{AP} /$ input scores based on the promoter proximal $500 \mathrm{bp}$ region of each gene and confirmed a greater dynamic range in this region as compared to the 'whole gene' window. The average IQR for the 500 bp promoter proximal region was 0.224 , approximately $60 \%$ greater than that observed for the "whole gene' analysis (Fig. 3b and Additional file 1: Table S4B). Additionally, we find that the minimum and maximum values span a wider range $(0.62-2.12)$ than that of the 'whole gene' (0.77-1.78). Plots of promoter proximal AP/ input scores by rank show a greater (vertical) spread in scores; with averaged accessibility scores for the middle $80 \%$ of genes covering a 1.7 -fold range, from 0.86 to 1.43 , while the average of the top and bottom $5 \%$ of scores was 
a

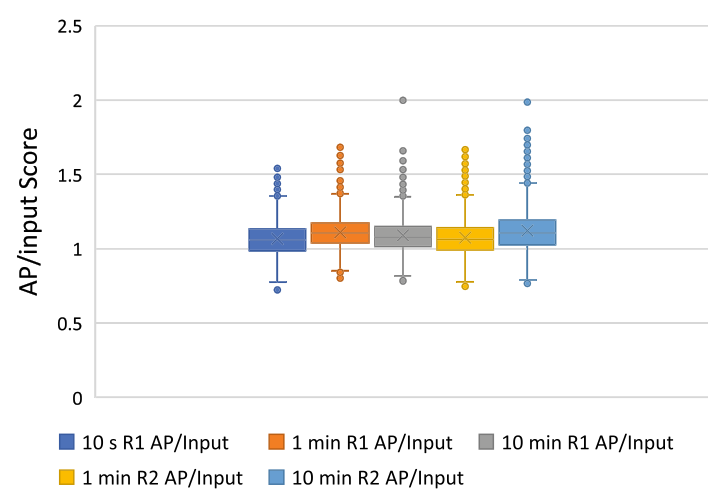

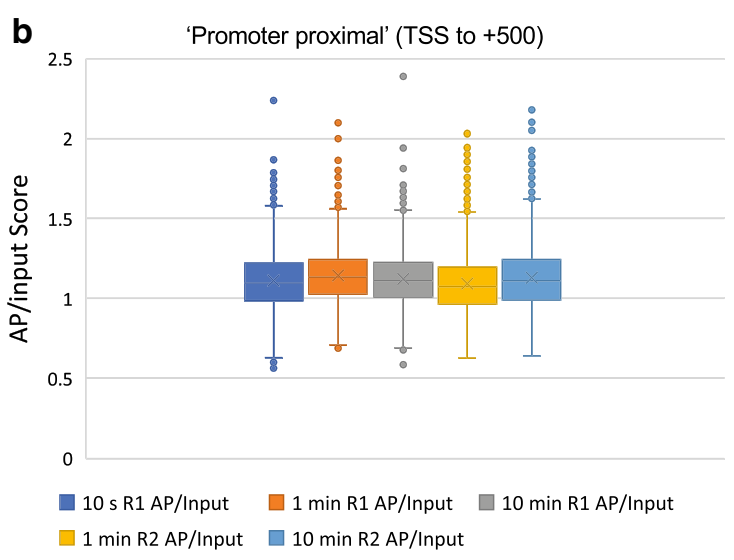

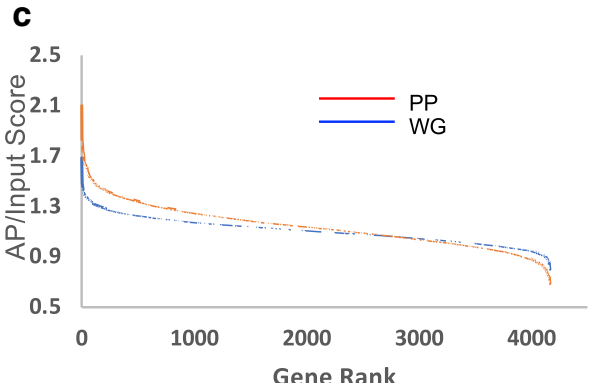

Fig. 3 Dynamic range of accessibility scores. Average AP/input scores for each gene were determined for 'whole gene' (a) and 'promoter proximal' (b) windows, as indicated, for each determination and plotted in box and whisker format. Shown are data from the $10 \mathrm{~s}$ (blue), $1 \mathrm{~min}$ (orange), and 10 min (grey) BM modification time points, and $1 \mathrm{~min}$ (yellow) and $10 \mathrm{~min}$ (light blue) replicate experiments. c Distribution of accessibility scores. The average AP/input scores for each gene were determined and plotted according to rank (1-4166) for the 'whole gene' -500 to +1500 (blue line, 'WG') and 'promoter proximal'TSS to +500 (orange line,'PP') windows for the 1 BM modification minute time point
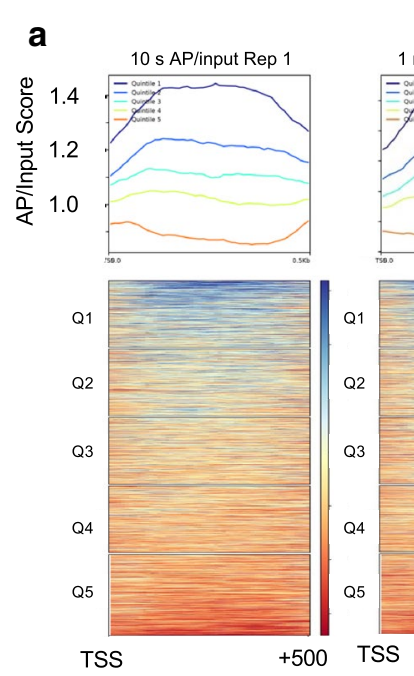

Q3
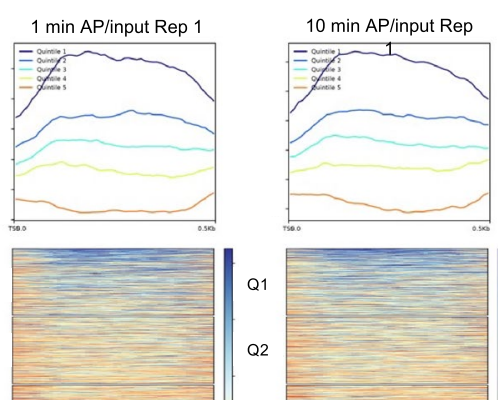
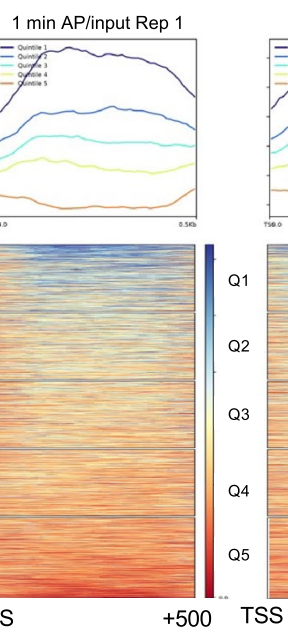

b

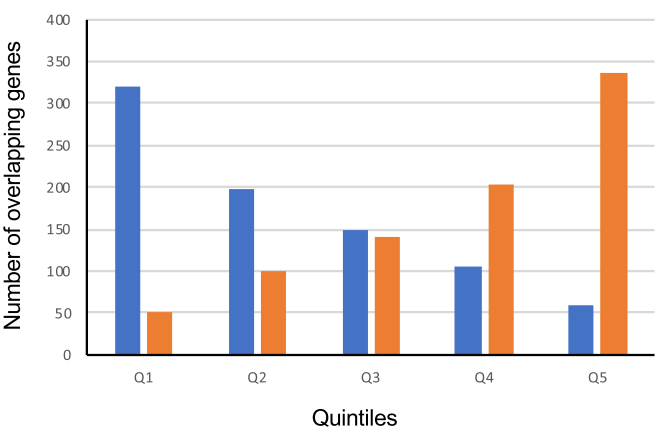

Fig. 4 Promoter proximal nucleosomes exhibit relatively larger differences in H2B S116C accessibility relative to the genomic average. a Genes were sorted according to AP/input scores averaged over the region TSS to $0.5 \mathrm{~kb}$, then binned into quintiles, with quintile 1 containing genes with the highest AP/input scores and quintile 5 containing the lowest scores. Top, plots of cumulative AP/input scores for each quintile, as shown in the heat map (bottom). $\mathbf{b}$ Distributions of most and least accessible genes in replicate experiments. Shown is the distribution of genes sorted into quintiles 1 (blue) and 5 (orange) for the 1 min BM modification experiment (Fig. 3a), in quintiles of a replicate experiment 
$1.55 \pm 0.12$ and $0.81 \pm 0.05$, respectively, a nearly twofold difference in average accessibility (Fig. 3c, orange line).

To investigate further, we grouped genes into ranked quintiles ( $\sim 833$ genes per quintile) according to average accessibility scores for the promoter proximal (TSS to $0.5 \mathrm{~kb}$ ) region. For all time points, the average of quintile 1 genes was $\sim 1.45$ while that for quintile 5 genes was $\sim 0.9$ (Fig. 4a), indicating nucleosomes within the first $500 \mathrm{bp}$ of genes in quintile 1 are $\sim 60 \%$ more accessible than those found in quintile 5 . In addition, we find that the promoter proximal input nucleosome reads are more similar across all quintiles than total AP reads, which exhibit a much broader distribution across quintiles, indicating discrimination between quintiles is primarily due to differential nucleosome modification and affinity purification (Additional file 1: Figure S1). Comparison of promoter proximal data exhibit similar, moderate levels of correlation among time points of modification and independent experiments, similar to the "whole gene" analysis (Additional file 1: Table S5, "All genes").

Given that the majority of genes in the center of the distributions exhibit small differences in average accessibility scores, we examined whether genes with more extreme accessibility values were more strongly correlated with each other across data sets. Because the majority of genes differ in accessibility only modestly, we reasoned that this contributed to the moderate Pearson correlation score and that greater Pearson correlation scores would be observed for the most and least accessible genes, Q1 and Q5, respectively. We assessed correlations independently between genes in quintiles 1 and 5 and for quintiles 2-4 for all data sets (Additional file 1: Table S5). Indeed, we find that there is greater correlation amongst quintiles 1 and 5 (average Pearson correlation

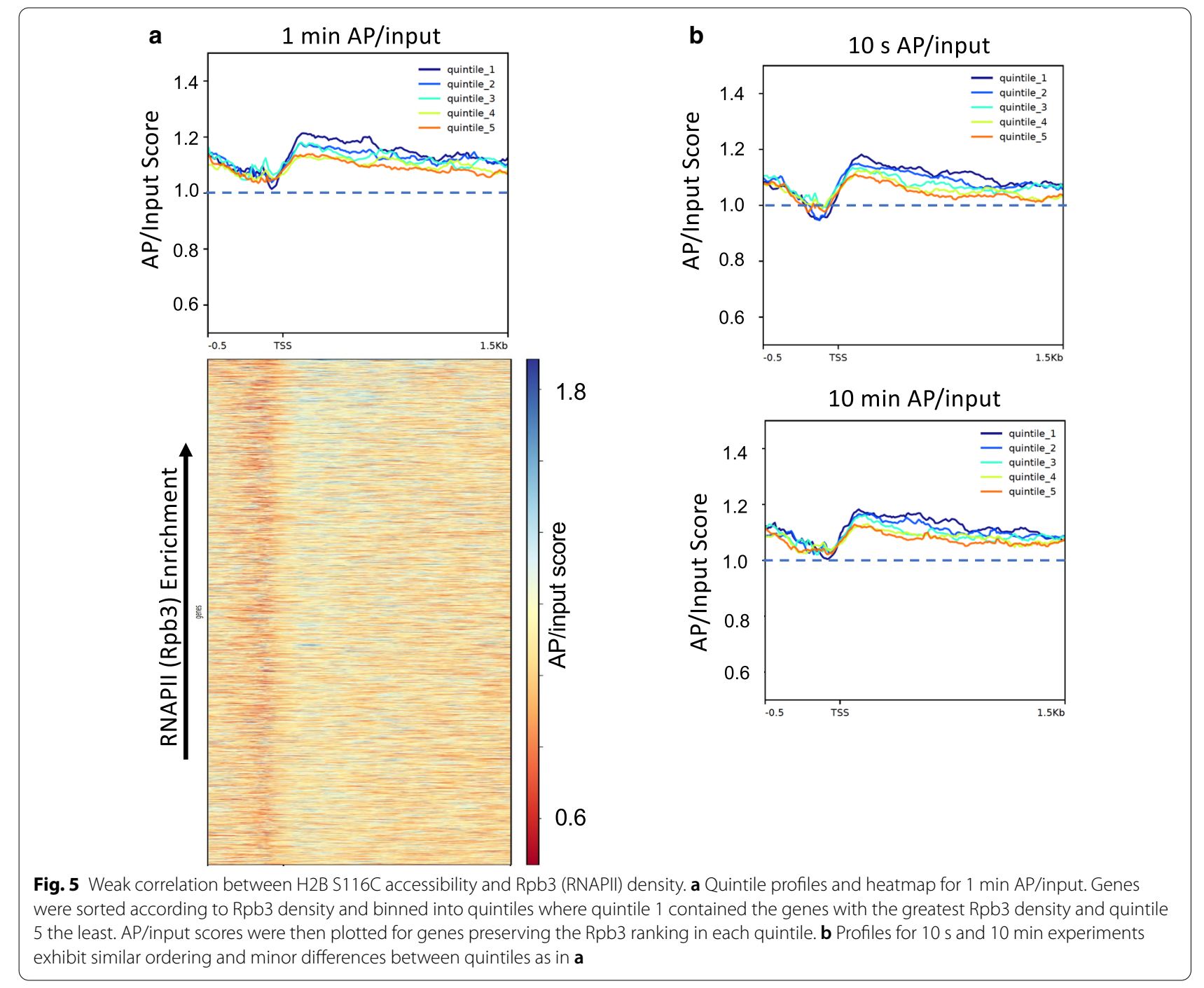


$0.439)$ compared to that for all quintiles (0.320) and even more so amongst quintiles 2-4 (average Pearson correlation 0.158). Moreover, a plot of the distribution of genes comprising quintiles 1 and 5 shows that each is found with highest probability in the same quintiles in a replicate experiment (Fig. 4b). Overall, this suggests that while a number of nucleosomes exhibit similar external surface accessibilities, those which exhibit higher and lower scores are not random as these are more strongly correlated with each other across modification time points. This implies that some external nucleosome surfaces in $S$. cerevisiae may in fact be related to nuclear processes.

\section{Nucleosome surface accessibility is only weakly correlated with RNAPII occupancy}

Since transcriptionally active chromatin is thought to exist as a more open chromatin structure, we hypothesized that H2B S116C accessibility would positively correlate with active transcription. Genes were sorted into quintiles using ChIP-seq data from an RNA polymerase II subunit, Rpb3 [48]. Quintile 1 contained the genes with the greatest Rpb3 density while quintile 5 contained the genes with the least. We then plotted the AP/ input values for these genes to determine whether genes with more Rpb3, and presumably more transcriptionally active, had more accessible external nucleosome surfaces. We found that genes within quintile 1 with the greatest Rpb3 density exhibit only $\sim 10 \%$ greater accessibility scores on average compared to quintile 5 , with the least $\mathrm{Rpb} 3$ density, regardless of modification time (Fig. 5a, b). Despite our finding that accessibility increased with Rpb3 density, the absolute difference in average accessibility between each successive quintiles was extremely small (Fig. 5a, b). Upon plotting accessibility values for genes sorted according to Rpb3 density, we find that the most and least accessible genes are in many cases not the genes with the greatest or least Rpb3 density, respectively (Fig. 5a, heatmap). Further, accessibility over the gene units and Rpb3 density over the first 500 bp exhibit a very weak Pearson correlation of 0.128 . Additionally, we investigated the relationship between $\mathrm{H} 2 \mathrm{~B}$ S116C accessibility and transcription elongation, by sorting genes according to publicly available NET-Seq data, and comparing to accessibility score [49]. Similar to the results for RNAPII (rpb3), we found virtually no relationship between these parameters, with a Pearson correlation of $\sim 0.039$ (Additional file 1: Figure S2).

While in these analyses, we focused on nucleosomesized DNA fragments, we considered the possibility that nucleosome loss on the most highly transcribed genes or loss of $\mathrm{H} 2 \mathrm{~A} / \mathrm{H} 2 \mathrm{~B}$ dimers reduces the correlation, and that more heavily transcribed genes with one or both copies of the $\mathrm{H} 2 \mathrm{~A} / \mathrm{H} 2 \mathrm{~B}$ dimer displaced due to disruption by
RNAPII, would be expected to be more susceptible to enzymatic digestion resulting in DNA fragments smaller than core particle size $(\sim 147 \mathrm{bp})[48,50]$. To investigate this, we assessed possible enrichment of complexes containing DNA lengths $90 \mathrm{bp}$ to $135 \mathrm{bp}$, which would correspond to digestion products from nucleosomes lacking $\mathrm{H} 2 \mathrm{~A} / \mathrm{H} 2 \mathrm{~B}$. Unlike fragment lengths corresponding to canonical nucleosomes (135 bp to $165 \mathrm{bp}$ ) we find that there is essentially no difference in $\mathrm{AP} /$ input score for subnucleosome length fragments (Additional file 1: Figure S3). Therefore, we decided to investigate the relationship between accessibility and chromatin remodelers that assist in poising genes for transcription as well as reconstituting nucleosome spacing, which mitigates cryptic transcription [51-53].

\section{Chromatin remodelers correlate with nucleosome surface accessibility}

Similar to our investigation of the relationship between accessibility and RNAPII (Rpb3 ChIP), we investigated the relationship between nucleosome accessibility and RSC, SWI/SNF and ISW1a chromatin remodelers by sorting genes according to their density of Rsc8, Snf2, and Ioc3, respectively [53], then plotted AP/input scores according to this gene order to determine whether accessibility and remodeler presence were correlated. RSC is known to restructure and evict nucleosomes within and near the promoter region to facilitate transcription [53]. Unlike Rpb3, we observe a moderate positive correlation over the first 500 bp between RSC density and accessibility scores (Pearson correlation coefficient 0.36 , average of all three time points) between accessibility and Rsc8 density (Fig. 6a). In contrast, ISW1a (Ioc3), consistent with its antagonistic function with respect to RSC [53-55] exhibited an opposite, but weaker correlation with accessibility scores in the promoter proximal region (Pearson correlation coefficient of -0.27) (Fig. 6b). Interestingly, the relationship between accessibility scores and Snf2 was similar to that of Ioc3 with an average Pearson correlation coefficient of -0.28 (Fig. 6c). While we find that nucleosome accessibility correlates with remodeler presence, we extended the analysis described above focusing on genes showing the greatest differences in accessibility. We found quintiles 1 and 5 are much more strongly correlated to chromatin remodeler occupancy compared to quintiles $2-4$, with average Pearson correlations of $0.49,-0.37$ and -0.37 for RSC, ISW1a and SWI/SNF respectively, compared to 0.16 , -0.12 and -0.13 for RSC, ISW1a and SWI/SNF, respectively for quintiles 2-4 (Additional file 1: Table S6). Thus, similar to the correlations between time course data sets, lower correlations for remodelers appear predominantly driven by the fact that the majority of nucleosomes and 

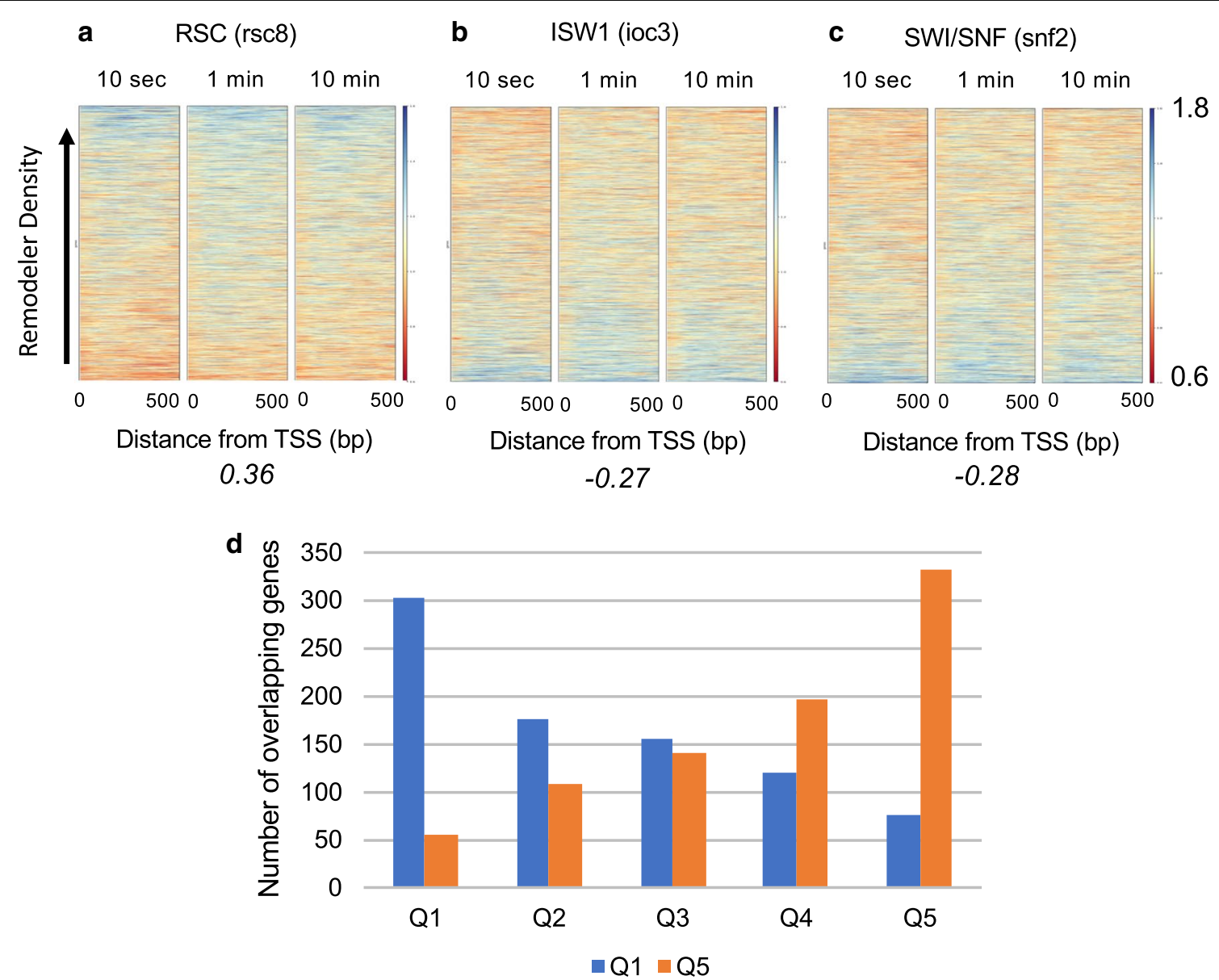

Fig. 6 H2B S116C accessibility correlates with chromatin remodelers. Genes were sorted according to remodeler density (Rsc8, loc3 and Snf2) and AP/input scores were then plotted for genes preserving the remodeler sorting for RSC (a), ISW1a (b) and SWI/SNF (c). Average Pearson correlation coefficients for each remodeler with H2B S116C accessibility are shown below each heatmap. $\mathbf{d}$ Overlap of most accessible (Q1) and least accessible genes (Q5) from the $1 \mathrm{~min}$ AP/input experiment with genes sorted by RSC density. For example, 300 genes which are in quintile 1 (Q1) based on accessibility, are also in Q1 for RSC density

genes in yeast are equivalently accessible. In addition, chromatin remodelers are known for being difficult proteins to ChIP [56-58] and typically exhibit enrichments with less than a twofold dynamic range. We also note that RSC depletion results in movement of the -1 and +1 nucleosomes towards the NDR, and the change in NDR width for WT and Rsc8 depletion strains has been determined for all genes [59]. Therefore, we also investigated whether genes with NDRs affected by RSC depletion were associated with distinctive H2B S116C accessibilities. Genes were sorted according to change in NDR compared to H2B S116C accessibility data (Additional file 1: Figure S4). In contrast to the moderate positive correlation we observed with Rsc8 ChIP-seq data, we observe minimal, if any, correlation with RSC depletion-dependent change in NDR width (Additional file 1: Figure S4). These results suggest that the correlation between nucleosome surface accessibility and RSC occupancy we detected is not related to the role of RSC in defining the NDR.

\section{S. cerevisiae heterochromatic regions do not exhibit reduced nucleosome surface accessibility}

It is well known that the S. cerevisiae genome is largely euchromatic, however there are heterochromatic regions where gene expression is repressed. Genes within $20 \mathrm{~kb}$ of the telomeres have been found to be less transcriptionally active and in some instances are bound by the SIR complex which induces heterochromatin formation in S. cerevisiae [60-62]. Although found to produce far fewer transcripts compared to non-subtelomeric genes, we find that these genes exhibit overall accessibility scores that are slightly greater than those for all genes (Fig. 7a). Moreover, the ranges of scores were comparable to that of average genes, with ranked quintiles exhibit comparable 

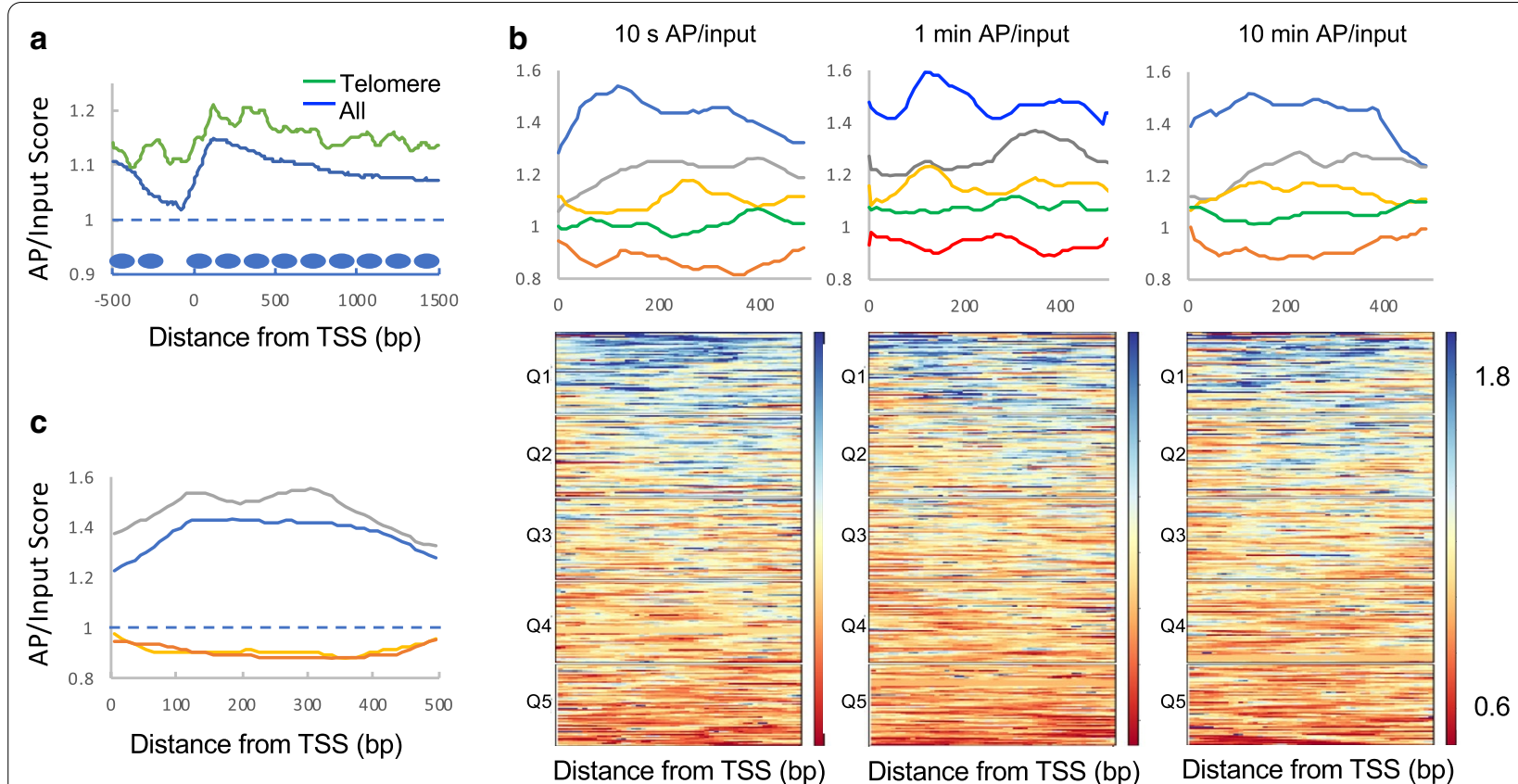

Fig. 7 The accessibility of $\mathrm{H} 2 \mathrm{~B}$ S116C in heterochromatic regions is commensurate with the genomic average. AP/input scores were determined for genes located within $20 \mathrm{~kb}$ of telomeres. a Comparison of aggregate scores for telomere-proximal genes (green line) and all genes (blue line). Nucleosomes positions are shown as in Fig. 1a. b Quintile analysis for three time points of BM modification. Quintiles 1-5 are plotted with blue, gray, yellow, green and red lines, respectively. Heat maps show individual quintiles. c Comparison of average scores for quintile 1 (telomere, gray; all genes, blue) and quintile 5 (telomere, orange; all genes, red)

accessibility profiles compared to all genes (Fig. 7b). Indeed, a comparison of accessibility scores for genes within the top and bottom quintiles for telomeres exhibit identical overall range compared to those for all genes (Fig. 7c). Moreover, similar to all genes, accessibility of telomere-proximal genes was uncorrelated with Rpb3 (Pol II) density (Pearson coefficient - 0.02). While initially surprising, this finding is in line with previous studies suggesting that $S$. cerevisiae heterochromatin does not silence gene expression via steric occlusion [63-65]. It should also be noted that the different modification times did not impact these findings. Our results for the H2B S116C surface site suggest that the chromatin in S. cerevisiae is not binary (i.e., open vs. condensed), but rather that changes in accessibility are more subtle, possibly as a consequence of nucleosome remodeling and positioning. To ensure that our standard nuclei resuspension conditions (buffer containing $75 \mathrm{mM} \mathrm{NaCl}$ and $0.5 \mathrm{MgCl}_{2}$ ) maintained folded structures, we repeated this experiment for the $1 \mathrm{~min}$ modification time point, using a nuclear resuspension buffer containing spermidine $(20 \mathrm{mM}$ PIPES $\mathrm{pH}$ 6.3, $1 \mathrm{M}$ sorbitol, $0.2 \mathrm{mM}$ spermidine) as polyamines have been shown to stabilize higher-order chromatin structures [66-69]. We find that these conditions yield similar results for remodeler density, transcriptional activity as gauged by Rpb3 density and for subtelomere gene accessibilities (Additional file 1: Figure S5A-C).

\section{Internal nucleosome surface sites are not significantly exposed genome-wide in yeast nuclei}

Previous reports indicated that nucleosomes isolated from transcriptionally active chromatin in S. cerevisiae at least transiently expose histone surfaces normally buried within the canonical nucleosome. For example, when present, the thiol group of $\mathrm{H} 3 \mathrm{C} 110$, which is normally buried within the 4-helix bundle comprising the H3$\mathrm{H} 3$ interface at the center of the nucleosome, was found to be accessible to organomercural-agarose columns in nucleosomes derived from transcriptionally active genes in yeast $[70,71]$. In addition, $\mathrm{H} 2 \mathrm{~A} / \mathrm{H} 2 \mathrm{~B}$ dimers are known to exhibit rapid turnover in transcriptionally active regions, suggesting the possibility that $\mathrm{H} 2 \mathrm{~A} / \mathrm{H} 2 \mathrm{~B}-$ $(\mathrm{H} 3 / \mathrm{H} 4)_{2}$ hexamers and $(\mathrm{H} 3 / \mathrm{H} 4)_{2}$ tetramers may transiently exist in genes being transcribed by RNAPII [ 50 , $72,73]$. We therefore generated yeast cells in which $\mathrm{H} 3$ was replaced with either H3 S102C or H3 A110C, which are buried within the canonical nucleosome structure to determine whether the $\mathrm{H} 2 \mathrm{~A}-\mathrm{H} 2 \mathrm{~B}$-hexamer interface or H3-H3 interface, respectively, are exposed genomewide in a manner that correlates with gene expression. Because such altered nucleosomes are likely to comprise 


\begin{tabular}{|c|c|c|c|}
\hline Sample & MNase & AP/input & $\begin{array}{l}\text { Fold } \\
\text { enrichment }\end{array}$ \\
\hline WT H3 & Low & 0.068 & 1.0 \\
\hline H3 S102C & Low & 0.044 & 0.65 \\
\hline $\mathrm{H} 3 \mathrm{~A} 110 \mathrm{C}$ & Low & 0.042 & 0.62 \\
\hline WT H3 & Medium & 0.018 & 1.0 \\
\hline H3 S102C & Medium & 0.017 & 0.94 \\
\hline WT H3 & High & 0.093 & 1.0 \\
\hline H3 S102C & High & 0.045 & 0.49 \\
\hline $\mathrm{H} 3 \mathrm{~A} 110 \mathrm{C}$ & High & 0.054 & 0.58 \\
\hline
\end{tabular}

Fold enrichment is calculated by dividing the ratio of AP/input of the mutant by that of the wild type. The AP/input ratios are determined by calculating the ratio of yeast:mouse aligned reads for each sample. Fold-enrichment values of $\sim 1$ or less indicate no enrichment for the internal $\mathrm{H} 3$ mutants

a minor proportion of nucleosomes at any point in time, we opted for a modification of $10 \mathrm{~min}$ to maximize detection. As nucleosomes with exposed internal surfaces are likely to be more rapidly digested to sub-nucleosomal products compared to bulk nucleosomes, we first examined enrichments from nucleosomes prepared under reduced MNase digestions conditions in which some dinucleosome and trinuclesome length DNA fragments remains, compared to primarily mononucleosome-sized fragments generated under standard conditions (Additional file 1: Figure S6A). Following library preparation of input and AP samples, we observed that there was no detectable enrichment of nucleosomes in the AP fraction from either mutant with respect to wild type (Table 1), with yeast/mouse DNA ratios for the mutants less than that of wild type (Additional file 1: Table S7, top). However, in this experiment where less extensive MNase digestion conditions were employed, we observed yeast/ mouse ratios slightly lower than expected, suggesting the less digested chromatin yielded increased background by preserving non-histone chromatin binding protein associations with the DNA. Therefore, we repeated this experiment using chromatin that was subjected to more extensive MNase digestion yielding predominantly 'core particle' length DNA fragments (Additional file 1: Figure $\mathrm{S} 6 \mathrm{~B})$. While the more extensive digestion resulted in yeast/mouse control ratios in line with expectation (Additional file 1: Table S7, bottom), similar to the underdigested chromatin, we found that yeast/mouse DNA rations of both mutants were slightly less than that of wild type suggesting that the recovered yeast DNA was background. We considered the possibility that exposure of these internal sites would involve disruption of the canonical nucleosome structure and thus more extensive trimming of DNA within such complexes by
MNase. However, we were unable to detect enrichment for shorter DNA lengths attributable to tetramer or hexamer histone-DNA complexes (Additional file 1: Figure S6A, S6B). Thus, for all digestion conditions attempted, we find that both of these internal mutants return DNA commensurate with background (Table 1 and Additional file 1: Table S7). Given that we were able to routinely achieve 25- to 50-fold enrichment for the H2B S116C surface site (see above), with $<5 \%$ of the nucleosomes modified, these data suggest that $<0.25 \%$ of all nucleosomes, we were unable to achieve enrichment above background with H3 S102C or H3 A110C.

\section{Discussion}

We employ a new method [36] to probe the accessibility of external and internal protein surfaces in nucleosomes genome-wide. We find that a cysteine installed on the nucleosome protein surface is widely exposed in the genome of $S$. cerevisiae. We anticipated that this site would be more exposed in open, transcribed euchromatic regions of the genome, but also exhibit reduced exposure, especially within known regions of heterochromatin and inactive genes. However, we find similar average accessibilities for nucleosomes within $0.5 \mathrm{~kb}$ upstream to $1.5 \mathrm{~kb}$ downstream with respect to the TSS of all yeast genes, including those within sub-temomeric heterochromatin regions. Somewhat greater variability in accessibility was found in 'promoter proximal' nucleosomes located within the first $500 \mathrm{bp}$ of genes, but even in this case the vast majority of genes exhibited accessibilities that differed by less than twofold. We designed our conditions to maintain the integrity of yeast chromatin in isolated nuclei, consistent with in vitro work demonstrating maximally folded chromatin states at salt concentrations commensurate with those used in this study [7]. Moreover, to confirm maintenance of fully compacted yeast chromatin we repeated the experiment with a spermidine buffer shown to achieve maximal compaction of chromatin in yeast nuclei [74], and found results identical to those obtained with our standard conditions. Thus, our data indicate that the external nucleosome surface accessibility as interrogated via H2B S116C is widely accessible throughout $S$. cerevisiae nuclei. Our findings are consistent with studies indicating minimal long-range inter-nucleosomal interactions in S. cerevisiae and that regulation of $S$. cerevisiae chromatin is regulated largely by local interactions $[13,75,76]$.

Our data also indicate that diffusion of BM through the nucleus occurs much more rapidly than cysteine modification, because accessibility differences are not affected by extent of modification. We find a high degree of correlation between AP data sets from $10 \mathrm{~s}$ and $10 \mathrm{~min}$ of modification (Pearson correlation 0.86), despite the large 
difference in the extent of modification between these two experiments (Fig. 1b). Moreover, all genes have nearly equivalent average scores based on their AP $10 \mathrm{~s} /$ AP 10 min ratio, indicating no subset of genes is systematically distinct (results not shown). These results indicate that nucleosomes exhibit a characteristic relative extent of modification regardless of the overall level of reaction, and that rate of $\mathrm{BM}$ diffusion does affect these values.

The vast majority of the budding yeast genome is genic, euchromatic and heavily acetylated and therefore would not be expected to possess long stretches of highly condensed chromatin. Our investigation of heterochromatic regions, which would presumably be most likely to contain higher-order chromatin structures involving 'faceto-face' nucleosome packing indicates that H2B S116C remains readily accessible. Analysis of genes within $20 \mathrm{~kb}$ of the telomeres yield accessibility scores that are on par with that observed for the remainder of the S. cerevisiae genome. Recent work has shown that $S$. cerevisiae heterochromatin, facilitated by Sir proteins, does condense but not to the extent of an oligonucleosome array in magnesium [77]. Additionally, it has been shown that S. cerevisiae heterochromatin does not hinder transcription through steric occlusion but rather specifically targets and prevents the transcriptional machinery from associating with the DNA [63, 64]. Early investigation into yeast chromatin structure found that the transcriptionally active DNA was as sensitive to DNase I digestion as the rest of the genome [78]. More recently, it was found that accessibility of DNA for euchromatic and heterochromatic regions were equivalent, commensurate with our finding that nucleosome external surface accessibilities were similar between these two chromatin states [65]. Although an earlier study identified higher-order chromatin structure in S. cerevisiae, more recent studies investigating $S$. cerevisiae chromatin structure did not identify long-range inter-nucleosomal interactions, indicative of higher-order chromatin structures, using electron cryotomography or chromatin conformation techniques [13, 75, 76, 79-81]. Additionally, it has been shown that organisms with greater nucleosome repeat lengths ( 197 bp or greater) more readily form compact chromatin structures including the $30 \mathrm{~nm}$ fiber as compared to shorter nucleosome repeat lengths (167 bp) [82]. Therefore, it is not surprising that us and others do not observe higher order chromatin structures in S. cerevisiae given that the nucleosome repeat length for this organism is $\sim 165 \mathrm{bp}$ [83].

We find that the accessibilities of nucleosomes within the first $500 \mathrm{bp}$ of gene transcription units exhibit a greater dynamic range, with approximately $50 \%$ difference between the least and most accessible quintiles.
While H2B S116C accessibility appears to be poorly correlated with Pol II levels, accessibility is moderately correlated with the presence of the RSC chromatin remodeler, exhibiting weaker negative correlations with SWI/SNF and ISW1a. In addition, we found no correlation between nucleosome surface accessibility and the effect of RSC on NDR width, suggesting other RSC functions are relevant to accessibility. It is interesting to note that while RSC depletion results in a loss of transcriptional activity as shown by total RNA analysis and a distinct change in transcription profile, RSC depletion does not alter overall nucleosome spacing or drastically change Pol II occupancy patterns [54, 84, 85]. Moreover, we find that transcription detected by NET-Seq shows little correlation with accessibility scores. These data are consistent with results indicating that RSC is weakly enriched on active genes [52]. Based these results we propose that RSC poises genes for transcription by increasing nucleosome accessibility prior to Pol II binding. After Pol II binding and initiation, the process of transcription results in nucleosome disruption along with rapid nucleosome reformation to limit cryptic transcription [86-90], resulting in less accessible chromatin on actively transcribed genes compared to genes poised for transcription. This effect may be due to nucleosome spacing, as most active genes have fewer nucleosomes and increased subnucleosomes [48], while the remaining nucleosomes have very short spacing which may reduce their accessibility [108]. Furthermore, nucleosomes and subnucleosomes located within the vicinity of promoters have been shown to associate with RSC, which may facilitate local exposure of the nucleosome surface [91, 92]. Indeed, analysis of restriction enzyme access and digestion of chromatin in S. cerevisiae and mouse hepatocytes showed that DNA accessibility is predominantly influenced by nucleosome spacing, and that enzyme accessibility is not correlated with gene activity [65].

Given the similar role to RSC in promoting gene expression, it was somewhat surprising to observe a negative correlation between SWI/SNF and nucleosome surface accessibility, similar to that observed between accessibility and ISWa. We note that RSC and SWI/ SNF exhibit a negative correlation among themselves $(-0.337)$, and that ISW1 and SWI/SNF occupancies are well correlated $(0.682)$. Because SWI/SNF is much less abundant than RSC and associated with a distinct cohort of genes compared to RSC, it is possible that the negative correlation is due to a lack of correspondence between the most accessible genes and those with greatest SWI/SNF density. SWI/SNF is an important component for transcriptional activation [93-97]. Therefore, it is possible that these genes are in a preliminary state of activation, being primed by SWI/SNF remodeling with 
downstream nucleosomes still maintaining regular spacing, limiting their accessibility. This is in contrast to RSC which has been shown to be a factor in transcription elongation [54, 98, 99]. Thus, it is possible that the accessibility of the external nucleosome surface in S. cerevisiae is dependent upon the transcriptional state (initiation vs. elongation) and more directly, the level of chromatin remodeling during these two states.

In stark contrast to the H2B S116C external surface site, we find little evidence of accessibility of two internal nucleosome sites installed on H3. Two residues on H3, H3 102 and H3 110, were selected to investigate the accessibility of internal nucleosome surfaces. Interestingly, prior studies have suggested that the $\mathrm{H} 3-\mathrm{H} 3$ interface in nucleosomes from transcriptionally active regions of chromatin is highly accessible in yeast, as well as chicken and HeLa cells [70, 71, 100, 101]. These studies selected for reactivity of $\mathrm{H} 3 \mathrm{~A} 110 \mathrm{C}$ (or H3 containing native cysteine at the 110 position) in preparations of nucleosome core particles (NCPs) using organomercurial affinity columns finding $\sim 20 \%$ of the total population of yeast nucleosomes were retained due to reaction with the thiol group within H3 A110C. Notably, it was reported that selected population contained nearly stoichiometric ratios of $\mathrm{H} 2 \mathrm{~A} / \mathrm{H} 2 \mathrm{~B}$ dimers and $\mathrm{H} 3 / \mathrm{H} 4$ tetramers and DNA fragment lengths typical for NCPs, suggesting little or no overall deviation from canonical nucleosome structure, as might be expected for nucleosomes with exposed H3-H3 interfaces [71]. In contrast, our experiments probed $\mathrm{H} 3$ C110 accessibilities in yeast nuclei containing unperturbed chromatin, and found no evidence for widespread non-canonical exposure of the $\mathrm{H} 3-\mathrm{H} 3$ interface. From experiments with $\mathrm{H} 2 \mathrm{~B}$ S116C mutants, we estimate that modification of $\sim 4 \%$ of nucleosomes in yeast nuclei resulted in an average of $\sim 40$-fold enrichment (Table 1, $1 \mathrm{~min}$ and $10 \mathrm{~min}$ modifications), while modification for $10 \mathrm{~s}$ resulted in about $0.4 \%$ of nucleosomes modified and yielded much smaller enrichments, about fivefold, but with signal still well above background. Assuming we could detect enrichment of half this amount of modification of $\mathrm{H} 3 \mathrm{~A} 110 \mathrm{C}$ nucleosomes, we estimate that no more than $0.2 \%$ of nucleosomes exist with exposed $\mathrm{H} 3-\mathrm{H} 3$ interfaces in native yeast nuclei clearly much less than the $\sim 20 \%$ detected in previous studies [70]. This discrepancy may be due to weakening of the $\mathrm{H} 3 / \mathrm{H} 3$ interface in the prior preparations of NCPs due to exposure to the organomecurial resin or other effects of the preparation of the NCPs from yeast nuclei, whereas we probed nucleosomes in native chromatin. Nevertheless, our data imply that the vast majority of nucleosomes within actively transcribed regions in yeast nuclei do not exhibit stable exposure of the H3-H3 interface, but rather exist as canonical nucleosomes.

We also probed for $\mathrm{H} 3$ 102, which is located at the $\mathrm{H} 2 \mathrm{~A}-\mathrm{H} 2 \mathrm{~B} / \mathrm{H} 3-\mathrm{H} 4$ interface and is exposed following removal of $\mathrm{H} 2 \mathrm{~A}-\mathrm{H} 2 \mathrm{~B}$ dimer. RNA polymerase II transcription occurs with transient disruption of the canonical nucleosome structure, resulting in $\mathrm{H} 2 \mathrm{~A}-\mathrm{H} 2 \mathrm{~B}$ dimer loss and, in the case of very high densities of RNAPII, even octamer eviction [48, 50, 72, 73, 102-105]. Additionally, heavily transcribed genes are more prone to lose nucleosome phasing, with reduced spacing and nucleosome occupancy [106-110]. While transcription does disrupt canonical nucleosome structure, nucleosomes are rapidly reformed, primarily resulting in exchange of $\mathrm{H} 2 \mathrm{~A} / \mathrm{H} 2 \mathrm{~B}$ dimers with free pools, along with some exchange of $\mathrm{H} 3 / \mathrm{H} 4$ tetramers [73, 105, 111-114]. Our results are consistent with the idea that chromatin reformation in the wake of transcribing RNAPII is extremely efficient.

In addition, such noncanonical nucleosome structures are expected to survive nuclei preparation and subsequent steps including washing of MNase digested chromatin fragments bound to the streptavidin-agarose resin, as $\mathrm{H} 3-\mathrm{H} 4$ tetramer dissociation from DNA occurs at $\sim 1.2 \mathrm{M} \mathrm{NaCl}$ [115-120]. Therefore, our wash buffers containing 0.15 and $0.6 \mathrm{M} \mathrm{NaCl}$ should not promote significant dissociation of DNA from resin-bound $\mathrm{H} 3-\mathrm{H} 4$ tetramers containing modified H3 S102C or H3 A110C.

\section{Conclusions}

Overall, we find that an external nucleosome surface site, H2B S116C, is widely accessible throughout the S. cerevisiae genome, including sub-telomeric regions, suggesting limited inter-nucleosomal interactions mediated by these surfaces. Furthermore, we find that the accessibility is modestly correlated with chromatin remodelers: RSC, ISW1a and SWI/SNF. RSC and accessibility exhibit a positive correlation whereas ISW1a and SWI/SNF exhibits a negative correlation. These results may indicate that for yeast, proper nucleosome spacing may be a primary driver of yeast chromatin structure and gene regulation. Consistent with this idea, we find that the accessibility of nucleosomes closest to the promoter is more dynamic than nucleosomes found upstream of the promoter and further downstream within gene bodies. Conversely, we find no evidence of widespread exposure of internal nucleosome surfaces suggesting that disruption of the canonical nucleosome structure and subsequent exposure of these sites is an extremely transient process.

\section{Supplementary Information}

The online version contains supplementary material available at https://doi. org/10.1186/s13072-020-00381-5. 
Additional file 1: Figure S1. Differences in accessibility scores (AP/input) seem to be influenced more by differences in AP reads (right) rather than input (left). Input and AP reads were plotted for each quintile. The range of AP scores is greater than that of the inputs which do not differ much between quintiles. Figure S2. Weak correlation between H2B S1 16C accessibility and nascent transcript (NET-seq) density. Genes were sorted according to NET-seq score and grouped into quintiles where quintile 1 contained the genes with the greatest nascent transcript density and quintile 5 the least. AP/input scores were then plotted for genes preserving the NET-seq sorting and grouping. All time points exhibit similar ordering and profiles and the difference between quintiles is minor. Figure S3. H2B S1 16C accessibility and RNAPII density are not correlated for subnucleosome length fragments (90-135 bp). Genes were sorted according to rpb3 density and grouped into quintiles where quintile 1 contained the genes with the greatest rpb3 density and quintile 5 the least as in Fig. 2. Only DNA fragments which were $90-135$ bp were included to investigate noncanonical nucleosomes which may be absent $\mathrm{H} 2 \mathrm{~A}-\mathrm{H} 2 \mathrm{~B}$ dimer. Figure S4. Nucleosome external surface accessibility does not exhibit obvious correlation with genes most affected by Rsc8 depletion. Genes were sorted according to change in NDR width following Rsc8 depletion (ref. [59]). This gene order was preserved and accessibility values for each time point was plotted from -500 to $500 \mathrm{bp}$ with respect to TSS. In contrast to the ChIP-seq data (Fig. 6), the positive correlation is no longer observed returning Spearman correlation coefficients of 0.06 , 0.04 and 0.04 for $10 \mathrm{~s}, 1 \mathrm{~min}$ and $10 \mathrm{~min}$, respectively. Note that spearman correlation was used here and is for TSS to $+500 \mathrm{bp}$ as the NDR width data were provided as rank of NDR width change. We find that Pearson and Spearman correlation coefficients are highly similar with our data. Figure S5. Alternative nuclei resuspension buffer yields all similar results for H2B S116C accessibility. A. Nuclei were resuspended in alternative buffer (20 mM PIPES pH 6.3, 1 M sorbitol, $0.2 \mathrm{mM}$ spermidine) to ensure folded chromatin structures were maintained. Accessibility scores were plotted according to remodeler density as in Fig. 6 and display similar correlations (Pearson correlations in italics above respective heatmap). B. Genes were sorted according to rpb3 density and grouped into quintiles as in Fig. 5. C. Average H2B S116C accessibility scores for all Polll genes and subtelomere genes as in Fig. 7. Figure S6. Extent of desired MNase digestion for internal H3 mutants. To preserve noncanonical nucleosome structures, accessibility of $\mathrm{H} 3$ mutants were investigated using less digested chromatin where the predominant species was greater than core particle size ( 147 bp). In S6A, digestion yielded predominantly mononucleosomes with $\sim 20$ bp of total linker DNA with the major peak being $\sim 170$ bp. In S6B, digestion conditions were used generating core particle length species with the major peak at $\sim 150 \mathrm{bp}$, similar to digestions for the H2B surface mutant. Table S1. Sequencing summary statistics for H2B S116C biotin-maleimide time course experiment. The total number of aligned reads for all samples is on the same order of magnitude [106]. However, the vast majority of the aligned reads for wild-type AP samples are found to be from the mouse DNA spike in control. Consequently, the ratio of aligned yeast reads to aligned mouse reads notably greater for the H2B S116C AP samples compared to the wild-type AP samples. Table S2. Fold enrichment and fraction of modified nucleosomes from WT and $\mathrm{H} 2 \mathrm{~B}$ S116C yeast nuclei. Fold enrichment was calculated by dividing AP/input of the mutant by that of the wild type. The AP/input ratio is determined by calculating the ratio of yeast:mouse aligned reads for each sample. The percentage of modified nucleosomes was determined by dividing the amount of AP DNA by the corrected input as determined in Tables S1, S2. All time points reveal signal above background with $1 \mathrm{~min}$ and $10 \mathrm{~min}$ time points averaging a fold enrichment of 43 . Percent of modified nucleosomes is corrected by subtracting the average apparent enrichment in the WT samples (0.08). Rep indicates replicate experiments. Bolded numbers are plotted in Fig. 1a. Table S3. Sequencing summary statistics for H2B S116C biotin-maleimide time course replicate experiments. The total number of aligned reads for all samples is on the same order of magnitude [106]. However, the vast majority of the aligned reads for wildtype AP samples are found to be from the mouse DNA spike in control. Consequently, the ratio of aligned yeast reads to aligned mouse reads notably greater for the H2B S116C AP samples compared to the wild-type AP samples. Table S4. Promoter-proximal nucleosomes exhibit greater differences in accessibility as compared to nucleosomes across genes.
AP/input accessibility scores were calculated for genes in two different windows, -500 to +1500 (A) and TSS +500 (B). Accessibility scores are more dynamic for promoter-proximal nucleosomes as compared to the nucleosomes throughout the region $-0.5 \mathrm{~kb}$ to $+1.5 \mathrm{~kb}$ with respect to the TSS. Table S5. Pearson correlation coefficients for accessibility scores within 500 bp of TSS. The average AP/input scores for each gene were determined from TSS to $500 \mathrm{bp}$ and the Pearson correlation was determined between each data set. Overall, these values are similar to those found from TSS to TTS (Fig. 1b). Table S6. Nucleosome accessibility correlate with remodeler density. Pearson correlations were determined for accessibility scores and remodeler density for all genes (A). Additionally, genes were grouped into quintiles based on remodeler density. Pearson correlations were then determined for accessibility and remodeler density scores for quintiles 1 and 5 (B) and quintiles 2-4 (C). Table S7. Sequencing summary statistics for internal nucleosome surface mutant sites. Yeast nuclei were modified and input and AP-selected nucleosome libraries prepared and sequenced as described in the text. $1 \mathrm{ng}$ of mouse DNA was added as a normalization control to all samples. Note the yeast/mouse DNA ratio in wild-type samples exceeds that of mutants suggesting no enrichment above background.

\section{Acknowledgements}

Not applicable.

\section{Authors' contributions}

LTM and JO were responsible for the performance of experiments and acquisition of data. LTM, DJC and JJH designed the work, and contributed to the analysis, and interpretation of data. All authors helped either drafted the work or substantively revise it. All authors have agreed to be accountable for all parts of the work. All authors read and approved the final manuscript.

\section{Funding}

This work was supported by National Institutes of Health Grants R01GM052426 (to JJH), T32GM068411 (to LM), and by the Intramural Research Program of the National Institutes of Health (DJC).

\section{Availability of data and materials}

The datasets used and/or analyzed during this current study are available from the corresponding author on reasonable request.

\section{Ethics approval and consent to participate}

Not applicable.

\section{Consent for publication}

Not applicable.

\section{Competing interests}

The authors declare that they have no competing interests.

\section{Author details}

${ }^{1}$ Department of Biochemistry and Biophysics, University of Rochester Medical Center, Rochester, NY 14642, USA. ${ }^{2}$ Instituto de Investigaciones en Ingeniería Genética y Biología Molecular "Dr. Héctor N. Torres" (INGEBI-CONICET), C1428ADN Buenos Aires, Argentina. ${ }^{3}$ Division of Developmental Biology, Eunice Kennedy Shriver National Institute of Child Health and Human Development, Bethesda, MD 20892, USA.

Received: 1 September 2020 Accepted: 28 December 2020 Published online: 11 January 2021

\section{References}

1. Pepenella S, Murphy KJ, Hayes JJ. Intra- and inter-nucleosome interactions of the core histone tail domains in higher-order chromatin structure. Chromosoma. 2014;123(1-2):3-13.

2. Grigoryev SA, Bascom G, Buckwalter JM, Schubert MB, Woodcock CL, Schlick T. Hierarchical looping of zigzag nucleosome chains in metaphase chromosomes. Proc Natl Acad Sci USA. 2016;113(5):1238-43. 
3. Maeshima K, Rogge R, Tamura S, Joti Y, Hikima T, Szerlong H, et al. Nucleosomal arrays self-assemble into supramolecular globular structures lacking 30-nm fibers. EMBO J. 2016;35(10):1115-32.

4. Garcia-Saez I, Menoni H, Boopathi R, Shukla MS, Soueidan L, NoirclercSavoye $\mathrm{M}$, et al. Structure of an $\mathrm{H} 1$-bound 6-nucleosome array reveals an untwisted two-start chromatin fiber conformation. Mol Cell. 2018;72(5):902.e7-915.e7.

5. Baldi S, Korber P, Becker PB. Beads on a string-nucleosome array arrangements and folding of the chromatin fiber. Nat Struct Mol Biol. 2020;27(2):109-18.

6. Livolant F, Mangenot S, Leforestier A, Bertin A, Frutos M, Raspaud E, et al. Are liquid crystalline properties of nucleosomes involved in chromosome structure and dynamics? Philos Trans A Math Phys Eng Sci. 1847;2006(364):2615-33.

7. Allahverdi A, Chen Q, Korolev N, Nordenskiold L. Chromatin compaction under mixed salt conditions: opposite effects of sodium and potassium ions on nucleosome array folding. Sci Rep. 2015;5:8512.

8. Korolev N, Allahverdi A, Yang Y, Fan Y, Lyubartsev AP, Nordenskiold L. Electrostatic origin of salt-induced nucleosome array compaction. Biophys J. 2010;99(6):1896-905.

9. Korolev N, Lyubartsev AP, Nordenskiold L. A systematic analysis of nucleosome core particle and nucleosome-nucleosome stacking structure. Sci Rep. 2018;8(1):1543.

10. Korolev N, Zhao Y, Allahverdi A, Eom KD, Tam JP, Nordenskiold L. The effect of salt on oligocation-induced chromatin condensation. Biochem Biophys Res Commun. 2012;418(2):205-10

11. Zinchenko A, Berezhnoy NV, Chen Q, Nordenskiold L. Compaction of single-molecule megabase-long chromatin under the influence of macromolecular crowding. Biophys J. 2018;114(10):2326-35.

12. Zinchenko A, Chen Q, Berezhnoy NV, Wang S, Nordenskiold L. Compaction and self-association of megabase-sized chromatin are induced by anionic protein crowding. Soft Matter. 2020;16(18):4366-72.

13. Chen C, Lim HH, Shi J, Tamura S, Maeshima K, Surana U, et al. Budding yeast chromatin is dispersed in a crowded nucleoplasm in vivo. Mol Biol Cell. 2016:27(21):3357-68

14. Cheung P, Allis CD, Sassone-Corsi P. Signaling to chromatin through histone modifications. Cell. 2000;103(2):263-71.

15. Strahl $B D$, Allis $C D$. The language of covalent histone modifications. Nature. 2000;403(6765):41-5.

16. Tse C, Sera T, Wolffe AP, Hansen JC. Disruption of higher-order folding by core histone acetylation dramatically enhances transcription of nucleosomal arrays by RNA polymerase III. Mol Cell Biol. 1998;18(8):4629-38.

17. Shogren-Knaak M, Ishii H, Sun JM, Pazin MJ, Davie JR, Peterson CL. Histone H4-K16 acetylation controls chromatin structure and protein interactions. Science. 2006;311(5762):844-7.

18. Allahverdi A, Yang R, Korolev N, Fan Y, Davey CA, Liu CF, et al. The effects of histone $\mathrm{H} 4$ tail acetylations on cation-induced chromatin folding and self-association. Nucleic Acids Res. 2011;39(5):1680-91.

19. Shogren-Knaak M, Peterson CL. Switching on chromatin: mechanistic role of histone H4-K16 acetylation. Cell Cycle. 2006:5(13):1361-5.

20. North JA, Simon M, Ferdinand MB, Shoffner MA, Picking JW, Howard $\mathrm{CJ}$, et al. Histone $\mathrm{H} 3$ phosphorylation near the nucleosome dyad alters chromatin structure. Nucleic Acids Res. 2014;42(8):4922-33.

21. Boeger H, Griesenbeck J, Strattan JS, Kornberg RD. Removal of promoter nucleosomes by disassembly rather than sliding in vivo. Mol Cell. 2004;14(5):667-73.

22. Lia G, Praly E, Ferreira H, Stockdale C, Tse-Dinh YC, Dunlap D, et al. Direct observation of DNA distortion by the RSC complex. Mol Cell. 2006;21(3):417-25.

23. Zhang Y, Smith CL, Saha A, Grill SW, Mihardja S, Smith SB, et al. DNA translocation and loop formation mechanism of chromatin remodeling by SWI/SNF and RSC. Mol Cell. 2006;24(4):559-68.

24. Zhu X, Liu B, Carlsten JO, Beve J, Nystrom T, Myers LC, et al. Mediator influences telomeric silencing and cellular life span. Mol Cell Biol. 2011;31(12):2413-21.

25. Wu C. The $5^{\prime}$ ends of Drosophila heat shock genes in chromatin are hypersensitive to DNase I. Nature. 1980;286(5776):854-60.

26. Wu C, Bingham PM, Livak KJ, Holmgren R, Elgin SC. The chromatin structure of specific genes: I. Evidence for higher order domains of defined DNA sequence. Cell. 1979;16(4):797-806.
27. Wu C, Wong YC, Elgin SC. The chromatin structure of specific genes: II. Disruption of chromatin structure during gene activity. Cell. 1979:16(4):807-14.

28. Giresi PG, Kim J, McDaniell RM, Iyer VR, Lieb JD. FAIRE (formaldehydeassisted isolation of regulatory elements) isolates active regulatory elements from human chromatin. Genome Res. 2007;17(6):877-85.

29. Buenrostro JD, Giresi PG, Zaba LC, Chang HY, Greenleaf WJ. Transposition of native chromatin for fast and sensitive epigenomic profiling of open chromatin, DNA-binding proteins and nucleosome position. Nat Methods. 2013;10(12):1213-8.

30. Buenrostro JD, Wu B, Chang HY, Greenleaf WJ. ATAC-seq: a method for assaying chromatin accessibility genome-wide. Curr Protoc Mol Biol. 2015:109:21-9.

31. Wal M, Pugh BF. Genome-wide mapping of nucleosome positions in yeast using high-resolution MNase ChIP-Seq. Methods Enzymol. 2012;513:233-50.

32. Lorzadeh A, Bilenky M, Hammond C, Knapp D, Li L, Miller PH, et al. Nucleosome density ChIP-Seq identifies distinct chromatin modification signatures associated with MNase accessibility. Cell Rep. 2016;17(8):2112-24.

33. Mieczkowski J, Cook A, Bowman SK, Mueller B, Alver BH, Kundu S, et al. MNase titration reveals differences between nucleosome occupancy and chromatin accessibility. Nat Commun. 2016;7:11485.

34. Mueller B, Mieczkowski J, Kundu S, Wang P, Sadreyev R, Tolstorukov MY, et al. Widespread changes in nucleosome accessibility without changes in nucleosome occupancy during a rapid transcriptional induction. Genes Dev. 2017:31(5):451-62.

35. Chereji RV, Bryson TD, Henikoff S. Quantitative MNase-seq accurately maps nucleosome occupancy levels. Genome Biol. 2019;20(1):198.

36. Marr LT, Clark DJ, Hayes JJ. A method for assessing histone surface accessibility genome-wide. Methods. 2019;184:61-9.

37. Dhillon N, Kamakaka RT. A histone variant, Htz1 p, and a Sir1 p-like protein, Esc2p, mediate silencing at HMR. Mol Cell. 2000;6(4):769-80.

38. Clark-Adams CD, Norris D, Osley MA, Fassler JS, Winston F. Changes in histone gene dosage alter transcription in yeast. Genes Dev. 1988;2(2):150-9.

39. Eriksson $P$, Thomas $L R$, Thorburn A, Stillman DJ. pRS yeast vectors with a LYS2 marker. Biotechniques. 2004;36(2):212-3.

40. Clonetech. Yeast protocols handbook. 2009. http://www.takara.co.kr/ file/manual/pdf/PT3024-1.pdf.

41. Cole HA, Howard BH, Clark DJ. Genome-wide mapping of nucleosomes in yeast using paired-end sequencing. Methods Enzymol. 2012;513:145-68

42. Langmead B, Salzberg SL. Fast gapped-read alignment with Bowtie 2 . Nat Methods. 2012;9(4):357-9.

43. Li H, Handsaker B, Wysoker A, Fennell T, Ruan J, Homer N, et al. The sequence alignment/map format and SAMtools. Bioinformatics. 2009;25(16):2078-9.

44. Ramirez F, Dundar F, Diehl S, Gruning BA, Manke T. deepTools: a flexible platform for exploring deep-sequencing data. Nucleic Acids Res. 2014;42(Web Server issue):W187-91.

45. Song F, Chen P, Sun D, Wang M, Dong L, Liang D, et al. Cryo-EM study of the chromatin fiber reveals a double helix twisted by tetranucleosomal units. Science. 2014;344(6182):376-80.

46. Takizawa Y, Ho CH, Tachiwana H, Matsunami H, Kobayashi W, Suzuki M, et al. Cryo-EM structures of centromeric tri-nucleosomes containing a central CENP-A nucleosome. Structure. 2020;28(1):44.e4-53.e4.

47. Luger K, Mäder AW, Richmond RK, Sargent DF, Richmond TJ. Crystal structure of the nucleosome core particle at 2.8 angstrom resolution. Nature. 1997;389(6648):251-60

48. Cole HA, Ocampo J, Iben JR, Chereji RV, Clark DJ. Heavy transcription of yeast genes correlates with differential loss of histone $\mathrm{H} 2 \mathrm{~B}$ relative to $\mathrm{H} 4$ and queued RNA polymerases. Nucleic Acids Res. 2014:42(20):12512-22.

49. Churchman LS, Weissman JS. Nascent transcript sequencing visualizes transcription at nucleotide resolution. Nature. 2011:469(7330):368-73.

50. Kireeva ML, Walter W, Tchernajenko V, Bondarenko V, Kashlev M, Studitsky VM. Nucleosome remodeling induced by RNA polymerase II: loss of the H2A/H2B dimer during transcription. Mol Cell. 2002;9(3):541-52. 
51. Ocampo J, Chereji RV, Eriksson PR, Clark DJ. The ISW1 and CHD1 ATPdependent chromatin remodelers compete to set nucleosome spacing in vivo. Nucleic Acids Res. 2016;44(10):4625-35.

52. Rawal Y, Chereji RV, Qiu H, Ananthakrishnan S, Govind CK, Clark DJ, et al. SWI/SNF and RSC cooperate to reposition and evict promoter nucleosomes at highly expressed genes in yeast. Genes Dev. 2018:32(9-10):695-710.

53. Parnell TJ, Schlichter A, Wilson BG, Cairns BR. The chromatin remodelers RSC and ISW1 display functional and chromatin-based promoter antagonism. Elife. 2015;4:e06073.

54. Ocampo J, Chereji RV, Eriksson PR, Clark DJ. Contrasting roles of the RSC and ISW1/CHD1 chromatin remodelers in RNA polymerase II elongation and termination. Genome Res. 2019:29(3):407-17.

55. Kubik S, Bruzzone MJ, Challal D, Dreos R, Mattarocci S, Bucher P, et al. Opposing chromatin remodelers control transcription initiation frequency and start site selection. Nat Struct Mol Biol. 2019;26(8):744-54.

56. Ng HH, Robert F, Young RA, Struhl K. Genome-wide location and regulated recruitment of the RSC nucleosome-remodeling complex. Genes Dev. 2002;16(7):806-19.

57. Whitehouse I, Rando OJ, Delrow J, Tsukiyama T. Chromatin remodelling at promoters suppresses antisense transcription. Nature. 2007:450(7172):1031-5.

58. Yen K, Vinayachandran V, Batta K, Koerber RT, Pugh BF. Genome-wide nucleosome specificity and directionality of chromatin remodelers. Cell. 2012;149(7):1461-73.

59. Ganguli D, Chereji RV, Iben JR, Cole HA, Clark DJ. RSC-dependent constructive and destructive interference between opposing arrays of phased nucleosomes in yeast. Genome Res. 2014;24(10):1637-49.

60. Wyrick JJ, Holstege FC, Jennings EG, Causton HC, Shore D, Grunstein M, et al. Chromosomal landscape of nucleosome-dependent gene expression and silencing in yeast. Nature. 1999;402(6760):418-21.

61. Tham WH, Zakian VA. Transcriptional silencing at Saccharomyces telomeres: implications for other organisms. Oncogene. 2002;21(4):512-21.

62. Ellahi A, Thurtle DM, Rine J. The chromatin and transcriptional landscape of native Saccharomyces cerevisiae telomeres and subtelomeric domains. Genetics. 2015;200(2):505-21.

63. Chen L, Widom J. Mechanism of transcriptional silencing in yeast. Cell. 2005;120(1):37-48.

64. Sekinger EA, Gross DS. Silenced chromatin is permissive to activator binding and PIC recruitment. Cell. 2001;105(3):403-14.

65. Chereji RV, Eriksson PR, Ocampo J, Prajapati HK, Clark DJ. Accessibility of promoter DNA is not the primary determinant of chromatin-mediated gene regulation. Genome Res. 2019;29(12):1985-95.

66. Hewish DR, Burgoyne LA. Chromatin sub-structure. The digestion of chromatin DNA at regularly spaced sites by a nuclear deoxyribonuclease. Biochem Biophys Res Commun. 1973;52(2):504-10.

67. Marion C, Roux B. Nucleosomes arrangement in chromatin. Nucleic Acids Res. 1978;5(11):4431-49.

68. Tjerneld F, Norden B, Wallin H. Chromatin structure studied by linear dichroism at different salt concentrations. Biopolymers. 1982:21(2):343-58.

69. Colson P, Houssier C. Polyamine addition to preparation media induces chromatin condensation, irreversibly at low ionic strength. FEBS Lett. 1989;257(1):141-4.

70. Chen TA, Smith MM, Le SY, Sternglanz R, Allfrey VG. Nucleosome fractionation by mercury affinity chromatography. Contrasting distribution of transcriptionally active DNA sequences and acetylated histones in nucleosome fractions of wild-type yeast cells and cells expressing a histone $\mathrm{H} 3$ gene altered to encode a cysteine 110 residue. J Biol Chem. 1991;266(10):6489-98

71. Walker J, Chen TA, Sterner R, Berger M, Winston F, Allfrey VG. Affinity chromatography of mammalian and yeast nucleosomes. Two modes of binding of transcriptionally active mammalian nucleosomes to organomercurial-agarose columns, and contrasting behavior of the active nucleosomes of yeast. J Biol Chem. 1990;265(10):5736-46.

72. Belotserkovskaya R, Oh S, Bondarenko VA, Orphanides G, Studitsky VM, Reinberg D. FACT facilitates transcription-dependent nucleosome alteration. Science. 2003;301(5636):1090-3.

73. Thiriet $\mathrm{C}$, Hayes JJ. Replication-independent core histone dynamics at transcriptionally active loci in vivo. Genes Dev. 2005;19(6):677-82.
74. Lohr D. The salt dependence of chicken and yeast chromatin structure. Effects on internucleosomal organization and relation to active chromatin. J Biol Chem. 1986;261(21):9904-14.

75. Hsieh TH, Weiner A, Lajoie B, Dekker J, Friedman N, Rando OJ. Mapping nucleosome resolution chromosome folding in yeast by micro-C. Cell. 2015;162(1):108-19.

76. Dekker J. Mapping in vivo chromatin interactions in yeast suggests an extended chromatin fiber with regional variation in compaction. J Biol Chem. 2008:283(50):34532-40.

77. Swygert SG, Senapati S, Bolukbasi MF, Wolfe SA, Lindsay S, Peterson CL. SIR proteins create compact heterochromatin fibers. Proc Natl Acad Sci USA. 2018;115(49):12447-52.

78. Lohr D, Hereford L. Yeast chromatin is uniformly digested by DNase-I. Proc Natl Acad Sci USA. 1979;76(9):4285-8.

79. Maeshima K, Imai R, Tamura S, Nozaki T. Chromatin as dynamic 10-nm fibers. Chromosoma. 2014;123(3):225-37.

80. Cai S, Song Y, Chen C, Shi J, Gan L. Natural chromatin is heterogeneous and self-associates in vitro. Mol Biol Cell. 2018:29(13):1652-63.

81. Lowary PT, Widom J. Higher-order structure of Saccharomyces cerevisiae chromatin. Proc Natl Acad Sci USA. 1989:86(21):8266-70.

82. Routh A, Sandin S, Rhodes D. Nucleosome repeat length and linker histone stoichiometry determine chromatin fiber structure. Proc Natl Acad Sci USA. 2008;105(26):8872-7.

83. Thomas JO, Furber V. Yeast chromatin structure. FEBS Lett. 1976;66(2):274-80.

84. Parnell TJ, Huff JT, Cairns BR. RSC regulates nucleosome positioning at Pol II genes and density at Pol III genes. EMBO J. 2008;27(1):100-10.

85. Hartley PD, Madhani HD. Mechanisms that specify promoter nucleosome location and identity. Cell. 2009;137(3):445-58.

86. Carrozza MJ, Li B, Florens L, Suganuma T, Swanson SK, Lee KK, et al. Histone $\mathrm{H} 3$ methylation by Set2 directs deacetylation of coding regions by Rpd3S to suppress spurious intragenic transcription. Cell. 2005;123(4):581-92.

87. Joshi AA, Struhl K. Eaf3 chromodomain interaction with methylated $\mathrm{H} 3-\mathrm{K} 36$ links histone deacetylation to Pol II elongation. Mol Cell. 2005;20(6):971-8

88. Keogh MC, Kurdistani SK, Morris SA, Ahn SH, Podolny V, Collins SR, et al. Cotranscriptional set2 methylation of histone $\mathrm{H} 3$ lysine 36 recruits a repressive Rpd3 complex. Cell. 2005;123(4):593-605.

89. Maltby VE, Martin BJ, Schulze JM, Johnson I, Hentrich T, Sharma A, et al. Histone $\mathrm{H} 3$ lysine 36 methylation targets the $\mathrm{Isw} 1 \mathrm{~b}$ remodeling complex to chromatin. Mol Cell Biol. 2012:32(17):3479-85.

90. Smolle M, Workman JL, Venkatesh S. reSETting chromatin during transcription elongation. Epigenetics. 2013;8(1):10-5.

91. Brahma S, Henikoff S. RSC-associated subnucleosomes define MNasesensitive promoters in yeast. Mol Cell. 2019;73(2):238.e3-249.e3.

92. Ramachandran S, Zentner GE, Henikoff S. Asymmetric nucleosomes flank promoters in the budding yeast genome. Genome Res. 2015:25(3):381-90.

93. Cote J, Peterson CL, Workman JL. Perturbation of nucleosome core structure by the SWI/SNF complex persists after its detachment, enhancing subsequent transcription factor binding. Proc Natl Acad Sci USA. 1998:95(9):4947-52.

94. Yudkovsky N, Logie C, Hahn S, Peterson CL. Recruitment of the SWI/SNF chromatin remodeling complex by transcriptional activators. Genes Dev. 1999;13(18):2369-74

95. Gutierrez JL, Chandy M, Carrozza MJ, Workman JL. Activation domains drive nucleosome eviction by SWI/SNF. EMBO J. 2007:26(3):730-40.

96. Deckert J, Struhl K. Targeted recruitment of Rpd3 histone deacetylase represses transcription by inhibiting recruitment of Swi/Snf, SAGA, and TATA binding protein. Mol Cell Biol. 2002;22(18):6458-70.

97. Schwabish MA, Struhl K. The Swi/Snf complex is important for histone eviction during transcriptional activation and RNA polymerase II elongation in vivo. Mol Cell Biol. 2007;27(20):6987-95.

98. Carey M, Li B, Workman JL. RSC exploits histone acetylation to abrogate the nucleosomal block to RNA polymerase II elongation. Mol Cell. 2006;24(3):481-7.

99. Spain MM, Ansari SA, Pathak R, Palumbo MJ, Morse RH, Govind CK. The RSC complex localizes to coding sequences to regulate Pol II and histone occupancy. Mol Cell. 2014;56(5):653-66. 
100. Allegra P, Sterner R, Clayton DF, Allfrey VG. Affinity chromatographic purification of nucleosomes containing transcriptionally active DNA sequences. J Mol Biol. 1987;196(2):379-88.

101. Chan S, Attisano L, Lewis PN. Histone H3 thiol reactivity and acetyltransferases in chicken erythrocyte nuclei. J Biol Chem. 1988;263(30):15643-51.

102. Schwabish MA, Struhl K. Evidence for eviction and rapid deposition of histones upon transcriptional elongation by RNA polymerase II. Mol Cell Biol. 2004:24(23):10111-7.

103. Kulaeva OI, Hsieh FK, Studitsky VM. RNA polymerase complexes cooperate to relieve the nucleosomal barrier and evict histones. Proc Natl Acad Sci USA. 2010;107(25):11325-30.

104. Rhee HS, Bataille AR, Zhang L, Pugh BF. Subnucleosomal structures and nucleosome asymmetry across a genome. Cell. 2014;159(6):1377-88.

105. Kimura $\mathrm{H}, \mathrm{Cook} P R$. Kinetics of core histones in living human cells: little exchange of $\mathrm{H} 3$ and $\mathrm{H} 4$ and some rapid exchange of $\mathrm{H} 2 \mathrm{~B}$. J Cell Biol. 2001;153(7):1341-53.

106. Field Y, Kaplan N, Fondufe-Mittendorf Y, Moore IK, Sharon E, Lubling $Y$, et al. Distinct modes of regulation by chromatin encoded through nucleosome positioning signals. PLoS Comput Biol. 2008;4(11):e1000216.

107. Shivaswamy S, Bhinge A, Zhao Y, Jones S, Hirst M, Iyer VR. Dynamic remodeling of individual nucleosomes across a eukaryotic genome in response to transcriptional perturbation. PLoS Biol. 2008;6(3):e65.

108. Zawadzki KA, Morozov AV, Broach JR. Chromatin-dependent transcription factor accessibility rather than nucleosome remodeling predominates during global transcriptional restructuring in Saccharomyces cerevisiae. Mol Biol Cell. 2009;20(15):3503-13.

109. Weiner A, Hughes A, Yassour M, Rando OJ, Friedman N. High-resolution nucleosome mapping reveals transcription-dependent promoter packaging. Genome Res. 2010:20(1):90-100.

110. Cui F, Cole HA, Clark DJ, Zhurkin VB. Transcriptional activation of yeast genes disrupts intragenic nucleosome phasing. Nucleic Acids Res. 2012;40(21):10753-64.

111. Mason PB, Struhl K. The FACT complex travels with elongating RNA polymerase II and is important for the fidelity of transcriptional initiation in vivo. Mol Cell Biol. 2003;23(22):8323-33.
112. Kaplan CD, Laprade L, Winston F. Transcription elongation factors repress transcription initiation from cryptic sites. Science. 2003:301(5636):1096-9.

113. Simic R, Lindstrom DL, Tran HG, Roinick KL, Costa PJ, Johnson AD, et al. Chromatin remodeling protein Chd 1 interacts with transcription elongation factors and localizes to transcribed genes. EMBO J. 2003;22(8):1846-56.

114. Nourani A, Robert F, Winston F. Evidence that Spt2/Sin1, an HMG-like factor, plays roles in transcription elongation, chromatin structure, and genome stability in Saccharomyces cerevisiae. Mol Cell Biol. 2006;26(4):1496-509.

115. Bohm V, Hieb AR, Andrews AJ, Gansen A, Rocker A, Toth K, et al. Nucleosome accessibility governed by the dimer/tetramer interface. Nucleic Acids Res. 2011;39(8):3093-102.

116. Park YJ, Dyer PN, Tremethick DJ, Luger K. A new fluorescence resonance energy transfer approach demonstrates that the histone variant $\mathrm{H} 2 \mathrm{AZ}$ stabilizes the histone octamer within the nucleosome. J Biol Chem. 2004:279(23):24274-82

117. Oohara I, Wada A. Spectroscopic studies on histone-DNA interactions. II. Three transitions in nucleosomes resolved by salt-titration. J Mol Biol. 1987;196(2):399-411.

118. Oohara I, Wada A. Spectroscopic studies on histone-DNA interactions. I. The interaction of histone $(\mathrm{H} 2 \mathrm{~A}, \mathrm{H} 2 \mathrm{~B})$ dimer with DNA: DNA sequence dependence. J Mol Biol. 1987;196(2):389-97.

119. Chen Y, Tokuda JM, Topping T, Sutton JL, Meisburger SP, Pabit SA, et al. Revealing transient structures of nucleosomes as DNA unwinds. Nucleic Acids Res. 2014:42(13):8767-76.

120. Hoch DA, Stratton JJ, Gloss LM. Protein-protein Forster resonance energy transfer analysis of nucleosome core particles containing $\mathrm{H} 2 \mathrm{~A}$ and H2A. Z. J Mol Biol. 2007;371(4):971-88.

\section{Publisher's Note}

Springer Nature remains neutral with regard to jurisdictional claims in published maps and institutional affiliations.
Ready to submit your research? Choose BMC and benefit from:

- fast, convenient online submission

- thorough peer review by experienced researchers in your field

- rapid publication on acceptance

- support for research data, including large and complex data types

- gold Open Access which fosters wider collaboration and increased citations

- maximum visibility for your research: over $100 \mathrm{M}$ website views per year

At BMC, research is always in progress.

Learn more biomedcentral.com/submissions 